\title{
AN ANALYSIS OF THE IMPACT OF SPORT UTILITY VEHICLES IN THE UNITED STATES
}

\author{
Stacy C. Davis \\ Lorena F. Truett
}

August 2000

Prepared for the

Office of Transportation Technologies

U.S. Department of Energy

Prepared by the OAK RIDGE NATIONAL LABORATORY

Oak Ridge, Tennessee 37831-6073

managed by

UT-BATTELLE, LLC

for the

U.S. DEPARTMENT OF ENERGY

under Contract No. DE-AC05-00OR22725 


\section{TABLE OF CONTENTS}

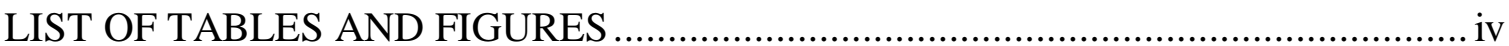

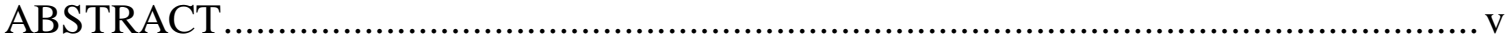

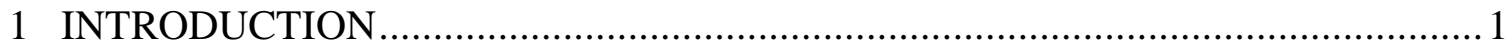

2 HISTORICAL GROWTH OF THE SUV MARKET ........................................... 1

3 ECONOMIC FACTORS AND MOBILITY TRENDS …..................................... 7

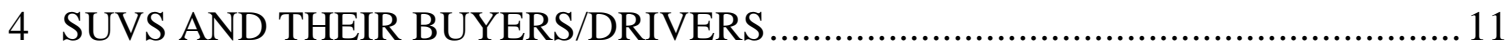

4.1 Vehicle Characteristics ........................................................................ 11

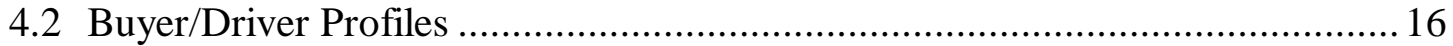

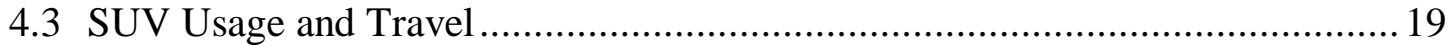

4.4 Why Buy a Sport Utility Vehicle? ........................................................ 21

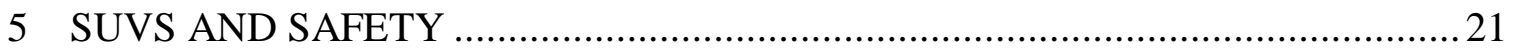

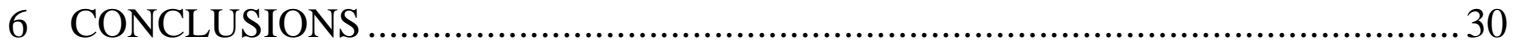

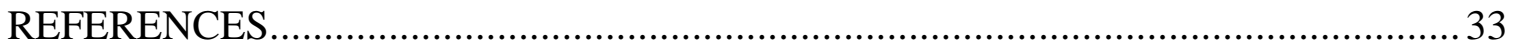

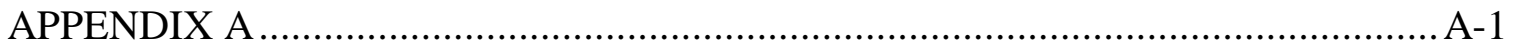

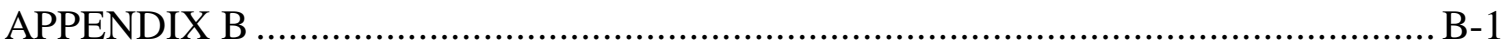




\section{LIST OF TABLES AND FIGURES}

\section{TABLES}

1 Currently Available SUVs by Size Category, Model Year 1999 ......................... 3

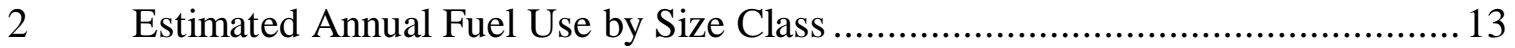

3 Emissions from a Typical New Car and Light Truck .................................. 15

$4 \quad$ Tow Ratings for Selected 1999 Models .................................................... 16

$5 \quad$ Average Annual Miles per Vehicle by Vehicle Type and Vehicle Age and Ratio of Vehicle Miles by Vehicle to Automobile Vehicle Miles ................ 19

6 Fatalities in SUV-Involved Crashes, 1980-1998, by SUV Size Category............22

7 Deaths per Million Passenger Vehicles 1-3 Years Old, 1998 ...........................25

8 Crashworthiness Evaluations: Frontal Offset Crash Test Performance................28

\section{FIGURES}

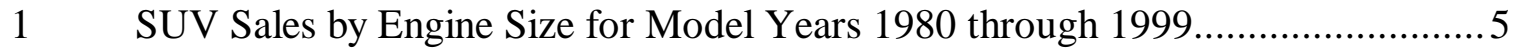

2 Shares of SUV Sales by Engine Size for Model Years 1980 through 1999 ..........5

3 Number of SUV Models by Engine Size for Model Years 1980 through 1999 ..... 5

4 Market Shares of Sales of SUVs in Comparison with Sales of Other

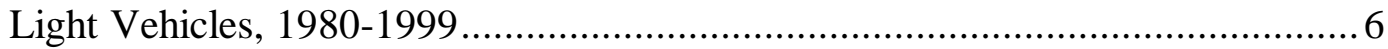

$5 \quad$ Forecast Sales of Light Vehicles Through the Year 2003 .............................. 7

6 Gross Domestic Product as a Measure of Economic Growth ............................ 8

7 Median Household Income, in Current and Constant 1996 Dollars, since 1980 .... 8

$8 \quad$ Average Gasoline Prices Since 1980 in Constant 1997 Dollars ........................... 9

9 Average Annual Vehicle Distance Traveled per Vehicle since 1980.................. 10

10 Sales-Weighted Fuel Economies by Vehicle Size Class, for Vehicles Weighing 8,500 Pounds or Less; Sales Period Covers 10/1/98-9/30/99 .............. 12

11 Comparison of Total Highway Fatalities and SUV-Involved Fatalities ...............23

12 Comparison of the Share of SUV Registrations to Total Registrations and the Share of SUV-Involved Fatalities to Total Fatalities, 1985-1998........... 23

13 Comparison of the Number of Total Registrations of All Vehicle Stock and the Number of Total Fatalities, 1985-1998 .............................................24

14 Fatality Rates for All Vehicles and for SUVs, Where Fatality Rate Is Defined as the Number of Fatalities per 100 Registered Vehicles..................... 24

15 Comparison of Fatalities for SUVs and Non-SUVs in Single-Vehicle Rollover and Non-rollover Fatal Crashes .27

16 Number of Fatalities for Multiple-Vehicle Crashes Involving SUVs, 1980-1998, by SUV Size and by SUV Occupant/Non-occupant Status. 


\begin{abstract}
During the 1990s, sport utility vehicles (SUVs) became the fastest growing segment of the auto industry, especially those in the medium-size category. In 1999, SUV sales reached almost $19 \%$ of the total light vehicle market and the mix of SUVs on the road, as measured by registration data, was about $8.7 \%$. This immense popularity has been called by some a passing fad - vehicle purchases based on the SUV “image." But the continued yearly increases in SUV sales seem to indicate a more permanent trend. Additional explanations for SUV popularity include the general economic wellbeing in the United States, a perception of safety, and "utility."
\end{abstract}

Generally larger and heavier than the typical automobile, SUVs require more fuel per mile to operate and produce greater amounts of pollutants. They are also driven further annually than are automobiles of the same vintage, a fact that exacerbates the fuel-use and emission problems.

Although buyers believe that SUVs are safer than automobiles which they are in some cases, SUVs are more prone to roll-overs than are automobiles. In addition, SUVs, with their higher bumpers and greater weight, may be a threat to other vehicles on the highway, especially in side-impact crashes.

With sales projected to grow to over 3 million units per year beginning in 2001, SUVs show no sign of decreasing in popularity. These vehicles are used primarily for general mobility, rather than off-road activities. An emphasis on better fuel economy and improved emissions control could address environmental and oil dependency concerns. In fact, recently, two vehicle manufacturers announced intentions of improving the fuel economy of their SUVs in the next few years. Also, tests simulating crashes involving automobiles and SUVs could provide valuable data for identifying potential safety design issues. It is clear that automobiles and SUVs will be sharing the highways for years to come. 


\section{AN ANALYSIS OF THE IMPACT OF SPORT UTILITY VEHICLES IN THE UNITED STATES}

It may be labeled sport utility vehicle, SUV, sport-ute, suburban assault vehicle, or a friend of OPEC (Organization for Petroleum Exporting Countries). It has been the subject of comics, the object of high-finance marketing ploys, and the theme of Dateline. Whatever the label or the occasion, this vehicle is in great demand. The popularity of sport utility vehicles (SUVs) has increased dramatically since the late 1970s, and SUVs are currently the fastest growing segment of the motor vehicle industry. Hoping to gain market share due to the popularity of the expanding SUV market, more and more manufacturers are adding SUVs to their vehicle lineup. One purpose of this study is to analyze the world of the SUV to determine why this vehicle has seen such a rapid increase in popularity. Another purpose is to examine the impact of SUVs on energy consumption, emissions, ${ }^{1}$ and highway safety.

\section{INTRODUCTION}

To analyze the impact of the rising popularity of SUVs, we look at the historical market share of SUVs and compare it with the market share of other types of personal vehicles. This examination compares sales trends of the SUV with sales of other types of vehicles. We also look at general economic trends in the United States as well as increases in personal mobility across all age groups. We look at other concerns, such as energy use and emissions, and at public perceptions of environmental problems. We examine buyer and driver profiles and review public opinion polls for anecdotal evidence. Finally, we examine safety issues.

\section{HISTORICAL GROWTH OF THE SUV MARKET}

Passenger vehicles are usually described by size (e.g., "compact") or price (e.g., "luxury"). The sport utility vehicle is available with engine sizes ranging from 1.6 to 6.5

\footnotetext{
${ }^{1}$ Including both criteria emissions and greenhouse gases (GHG).
} 
liters, curb weights from about 2,700 pounds to over 5,500 pounds, and price ranges ${ }^{2}$ from under $\$ 14,000$ to over $\$ 65,000$. It is, therefore, difficult to analyze SUVs without subdividing them into categories. Table 1 lists SUVs in three categories based on engine size. Other categories (e.g., price, weight, or wheelbase) would result in slightly different groupings. Throughout this report, unless otherwise noted, SUVs are described as being "small" (less than 3 liters), "medium" (3-5 liters), or "large" (greater than 5 liters) based on engine size. Some models have engine sizes in two categories; these models are placed in the category of the more popular engine size.

Figure 1 shows the sales of SUVs, in millions of vehicles per year, beginning in 1980. As shown in this figure, total sales climbed consistently beginning in the early 1980s and rose rapidly in the 1990s. The SUV market accounted for $7 \%$ of vehicle sales in 1990 and $19 \%$ in $1999 .{ }^{3}$ Figure 2 shows the distribution of total SUV sales among small, medium, and large SUVs since 1980. (A particular make-model could switch size categories from year to year if the engine size changed.) As shown in Figure 2, most SUV sales are for medium-sized vehicles, with engine displacements between 3.0 and 5.0 liters. Through the years, the large SUVs have maintained a small but consistent share of the SUV market. The medium and small SUVs have seen more fluctuation in their share of the SUV market; the majority of sales of small SUVs was between 1983 and 1987. In 1988, Consumers Union published reports indicating that small SUVs were less safe than other vehicles. Sales of small SUVs declined about that time, and sales of medium SUVs rose sharply.

When SUVs appeared to be increasing in popularity, many manufacturers added SUV models to their product listings. Figure 3 shows the growth in the number of SUV models since 1980. As a matter of clarification, many of these "different" models are actually the same basic vehicle with slightly different trim and a different name. ${ }^{4}$

\footnotetext{
${ }^{2}$ Price ranges represent 1999 model base price and are taken from Crain Communications, Automotive News, '99 Market Data Book, May 1999, pp. 75-81.

${ }^{3}$ Oak Ridge National Laboratory, Light Vehicle MPG and Market Shares System, 1999.

${ }^{4}$ Krebs, Michelle, "Vehicles So Much Alike They're Actually the Same," The New York Times, October 20, 1999.
} 
Table 1. Currently Available SUVs by Size Category, Model Year $1999^{a}$

\begin{tabular}{|c|c|c|c|c|c|c|c|c|c|c|c|c|c|c|c|}
\hline NAMEPLATE & $\begin{array}{c}\text { LITERS } \\
\text { (low } \\
\text { value) } \\
\end{array}$ & $\begin{array}{c}\text { LITERS } \\
\text { (high } \\
\text { value) } \\
\end{array}$ & HEIGHT & LENGTH & WIDTH & $\begin{array}{l}\text { WHEEL- } \\
\text { BASE }\end{array}$ & $\begin{array}{l}\text { CURB- } \\
\text { WEIGHT }\end{array}$ & $\begin{array}{c}\text { GROSS } \\
\text { VEHICLE } \\
\text { WEIGHT }\end{array}$ & $\begin{array}{l}\text { MY } 1999 \\
\text { SALES }\end{array}$ & $\begin{array}{l}\text { MY } 1998 \\
\text { SALES } \\
\end{array}$ & $\begin{array}{l}\mathrm{LOW} \\
\mathrm{MPG}^{b}\end{array}$ & $\begin{array}{l}\mathrm{HIGH} \\
\mathrm{MPG}^{b}\end{array}$ & $\begin{array}{c}\text { EST. } \\
\mathrm{GHG}^{c} \\
\text { (tons/yr) }\end{array}$ & $\begin{array}{c}\text { LOW } \\
\text { BASE } \\
\text { PRICE }^{d} \\
\end{array}$ & $\begin{array}{c}\text { HIGH } \\
\text { BASE } \\
\text { PRICE }^{d} \\
\end{array}$ \\
\hline \multicolumn{16}{|c|}{ Small SUVs (engine $<3.0$ liters) } \\
\hline CHEVROLET TRACKER & 1.6 & 2.0 & 66.5 & 148.8 & 66.7 & 86.6 & 2,717 & 3,100 & 32,569 & 21,672 & $22-25$ & $25-28$ & $11-12$ & $\$ 14,000$ & $\$ 16,300$ \\
\hline HONDA CR-V & 2.0 & - & 65.9 & 177.6 & 68.9 & 103.2 & 3,450 & 4,740 & 115,614 & 91,700 & $22-25$ & - & 12 & $\$ 19,000$ & $\$ 20,900$ \\
\hline ISUZU AMIGO & 2.4 & 3.2 & 66.6 & 167.8 & 70.4 & 96.9 & 3,466 & 4,650 & 9,972 & 4,146 & $17-21$ & $21-24$ & $12-15$ & $\$ 16,300$ & $\$ 20,745$ \\
\hline KIA SPORTAGE & 2.0 & - & 65.0 & 170.3 & 68.1 & 104.3 & 3,186 & 4,200 & 46,645 & 26,281 & $19-23$ & - & $13-14$ & $\$ 15,200$ & $\$ 19,000$ \\
\hline SUBARU FORESTER & 2.5 & - & 65.0 & 175.2 & 68.3 & 99.4 & 3,020 & 4,110 & 50,582 & 36,521 & $21-26$ & $21-27$ & $12-13$ & $\$ 19,200$ & $\$ 22,700$ \\
\hline SUZUKI SIDEKICK 2DOOR & 1.7 & - & 65.1 & 143.7 & 65.2 & 86.6 & 2,756 & 3,307 & 669 & 18,248 & $23-26$ & - & $11-12$ & $\$ 13,500$ & $\$ 19,800$ \\
\hline SUZUKI GRAND VITARA & 2.5 & - & 68.5 & 164.6 & 70.1 & 97.6 & 3,197 & 3,990 & 24,222 & 1,557 & $18-20$ & $19-22$ & $11-14$ & $\$ 18,400$ & $\$ 20,400$ \\
\hline SUZUKI VITARA 2 DOOR & 1.6 & 2.0 & 66.5 & 152.0 & 67.3 & 86.6 & 2,723 & 3,373 & 4,666 & - & $22-25$ & $25-28$ & $11-12$ & $\$ 13,900$ & $\$ 18,400$ \\
\hline TOYOTA RAV4 & 2.0 & - & 64.8 & 147.2 & 66.7 & 86.6 & 2,500 & 3,649 & 61,942 & 65,260 & $22-26$ & $24-29$ & $7-12$ & $\$ 16,100$ & $\$ 18,200$ \\
\hline SALES-WEIGHTED AVG. & & & 65.7 & 168.7 & 68.7 & 98.3 & 3,238 & & & & & & & $\$ 17$ & \\
\hline \multicolumn{16}{|c|}{ Medium SUVs (3.0 liters <= engine $<5.0$ liters) } \\
\hline ACURA SLX & 3.5 & - & 72.2 & 181.3 & 72.2 & 108.7 & 4,615 & 4,740 & 689 & 1,722 & $15-19$ & - & 17 & $\$ 36,800$ & - \\
\hline CHEVROLET S10 BLAZER & 4.3 & - & 64.5 & 176.8 & 67.8 & 100.5 & 3,848 & 4,850 & 220,197 & 225,044 & $15-18$ & $17-23$ & $14-16$ & $\$ 19,000$ & $\$ 33,300$ \\
\hline FORD EXPLORER & 4.0 & 4.9 & 67.9 & 178.6 & 70.2 & 101.7 & 3,919 & 4,811 & 439,250 & 415,362 & $14-19$ & $18-23$ & $15-18$ & $\$ 20,600$ & $\$ 35,100$ \\
\hline GMC JIMMY & 4.3 & - & 66.9 & 177.3 & 67.8 & 100.5 & 3,848 & 4,850 & 72,527 & 72,146 & $15-18$ & $17-23$ & $14-16$ & $\$ 19,100$ & $\$ 31,600$ \\
\hline GMC ENVOY & 4.3 & - & 64.2 & 183.8 & 67.8 & 107.0 & 4,049 & 5,350 & & - & $15-18$ & - & $\mathrm{n} / \mathrm{a}$ & $\$ 34,125$ & - \\
\hline HONDA PASSPORT & 3.2 & - & 68.5 & 177.4 & 70.4 & 106.4 & 3,860 & $\mathrm{n} / \mathrm{a}$ & 24,826 & 24,677 & $16-20$ & $18-21$ & 15 & $\$ 23,100$ & $\$ 29,400$ \\
\hline INFINITI QX4 & 3.3 & - & 70.7 & 183.9 & 72.4 & 106.3 & 4,275 & 5,150 & 21,194 & 17,818 & $15-19$ & - & 17 & $\$ 36,000$ & - \\
\hline ISUZU RODEO & 2.2 & 3.2 & 66.1 & 176.7 & 70.4 & 106.4 & 4,700 & 4,850 & 61,997 & 59,306 & $16-20$ & $21-24$ & $13-15$ & $\$ 18,700$ & $\$ 31,100$ \\
\hline ISUZU TROOPER & 3.5 & - & 72.2 & 181.3 & 72.2 & 108.7 & 4,455 & 5,510 & 19,018 & 15,679 & $15-19$ & $16-19$ & $16-17$ & $\$ 27,600$ & - \\
\hline ISUZU VEHICROSS & 3.5 & - & 66.9 & 162.6 & 70.5 & 91.8 & 3,955 & 4,652 & 889 & - & $15-19$ & - & 15 & $\$ 29,400$ & - \\
\hline JEEP CHEROKEE & 2.5 & 4.0 & 64.0 & 167.5 & 69.4 & 101.4 & 3,360 & 4,900 & 162,430 & 143,786 & $16-21$ & $21-25$ & $12-15$ & $\$ 16,600$ & $\$ 23,200$ \\
\hline JEEP WRANGLER & 2.5 & 4.0 & 71.1 & 153.0 & 66.7 & 93.4 & 3,216 & 4,450 & 88,908 & 82,098 & $15-18$ & $18-20$ & $14-16$ & $\$ 14,900$ & $\$ 20,700$ \\
\hline JEEP GRAND CHEROKEE & 4.0 & 4.7 & 69.4 & 181.5 & 72.3 & 105.9 & 3,932 & $\mathrm{n} / \mathrm{a}$ & 288,264 & 238,478 & $15-19$ & $16-21$ & 19 & $\$ 26,500$ & $\$ 34,700$ \\
\hline LAND ROVER DEFENDER & 3.9 & - & 90.0 & 181.1 & 70.5 & 110.0 & 4,840 & $\mathrm{n} / \mathrm{a}$ & 10 & 759 & $15-19$ & - & $\mathrm{n} / \mathrm{a}$ & $\$ 34,600$ & - \\
\hline $\begin{array}{l}\text { LAND ROVER } \\
\text { DISCOVERY II }\end{array}$ & 3.9 & - & 77.4 & 178.7 & 70.6 & 100.0 & 4,465 & 6,019 & 19,590 & 13,057 & $13-16$ & $14-17$ & $18-19$ & $\$ 34,800$ & - \\
\hline $\begin{array}{l}\text { LAND ROVER RANGE } \\
\text { ROVER }\end{array}$ & 3.9 & 4.6 & 71.6 & 185.5 & 74.4 & 108.1 & 4,960 & 6,130 & 7,454 & 6,866 & $13-16$ & - & 19 & $\$ 58,600$ & $\$ 66,600$ \\
\hline LEXUS RX300 & 3.0 & - & 65.7 & 180.1 & 71.5 & 103.0 & 4,037 & 4,950 & 66,734 & 27,581 & $18-22$ & - & $\mathrm{n} / \mathrm{a}$ & $\$ 32,500$ & $\$ 33,900$ \\
\hline LEXUS LX450/470 & 4.7 & - & 72.8 & 192.5 & 76.4 & 112.2 & 5,401 & 6,470 & 15,281 & 1,168 & $13-16$ & - & 19 & $\$ 56,700$ & - \\
\hline
\end{tabular}




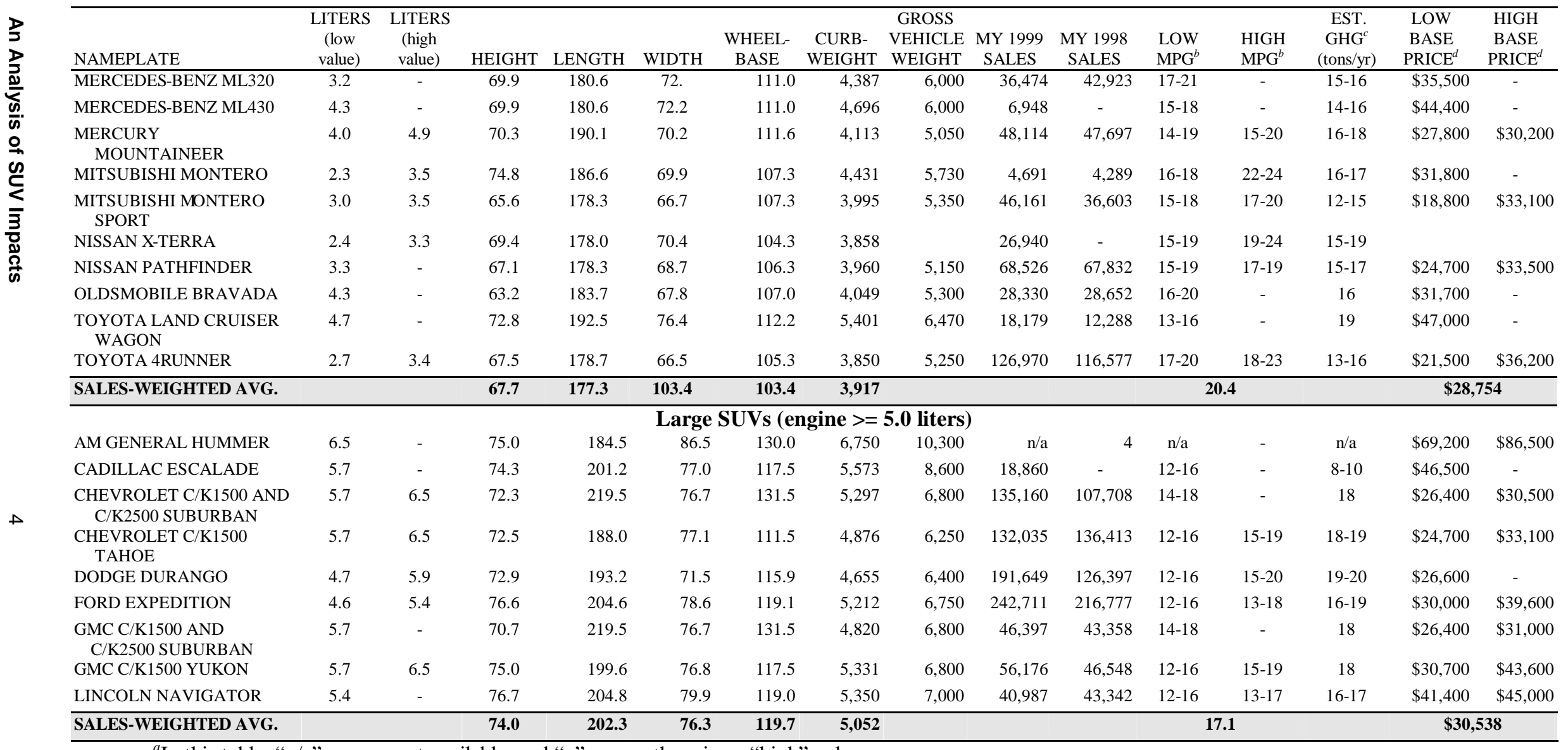

${ }^{a}$ In this table, "n/a" means n ot available, and "-." means there is no "high" value.

${ }^{b}$ Differences in miles -per-gallon (MPG) ranges are caused by factors such as two-wheel-drive (2WD) vs. four-wheel-drive (4WD), number of cylinders, and/or manual vs. automatic transmission.

${ }^{c} \mathrm{GHG}=$ green house gas.

${ }^{d}$ Differences in base price are based on factors such as $2 \mathrm{WD}$ vs. $4 \mathrm{WD}$, convertible or not, and/or 2 -door vs. 4-door.

Sources: Base prices from Crain Communications, Automotive News, '99 Market Data Book, May 1999, pp. 91-104, Model Year 1999. Sales and specifications are from the Oak Ridge National Laboratory Light Vehicle MPG and Market Shares System. Greenhouse gas emissions estimates are from DiCicco and Martin, "Green Guide to Cars and Trucks," Model Year 1998 and 1999 editions, American Coun cil for an Energy-Efficient Economy. 


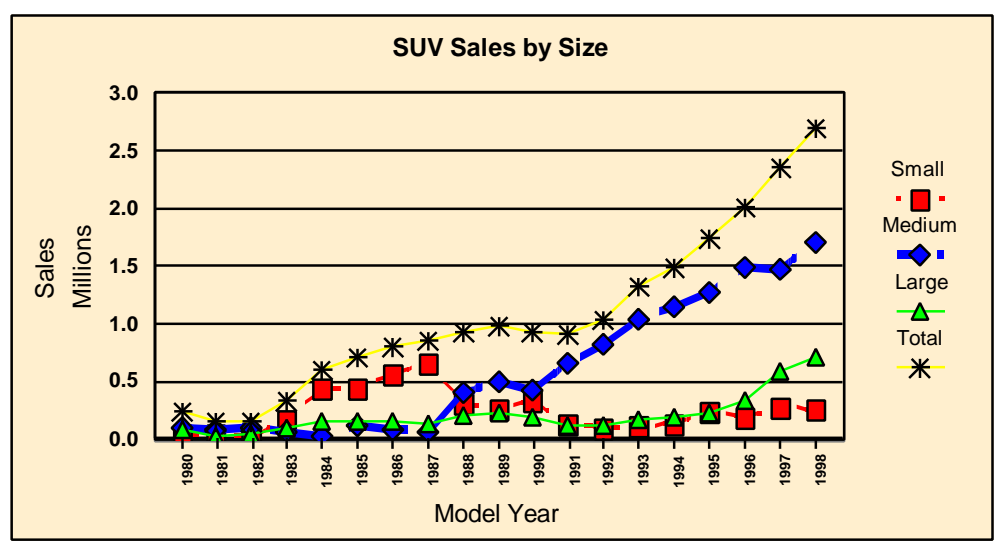

Figure 1. SUV Sales by Engine Size for Model Years 1980 through 1999.Source: Oak Ridge National Laboratory, Light Vehicle MPG and Market Shares System.

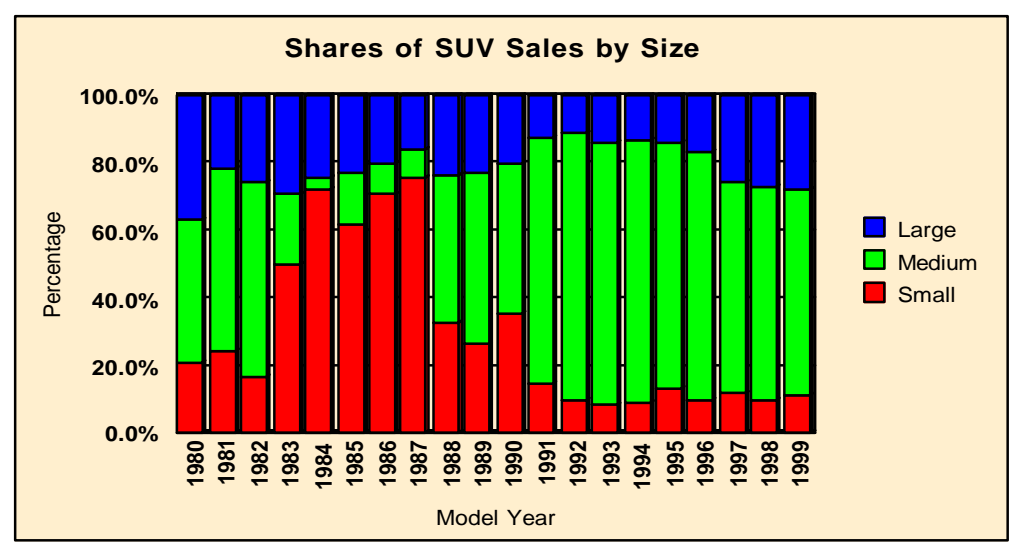

Figure 2. Shares of SUV Sales by Engine Size for Model Years 1980 through 1999. Source: Oak Ridge National Laboratory, Light Vehicle MPG and Market Shares System.

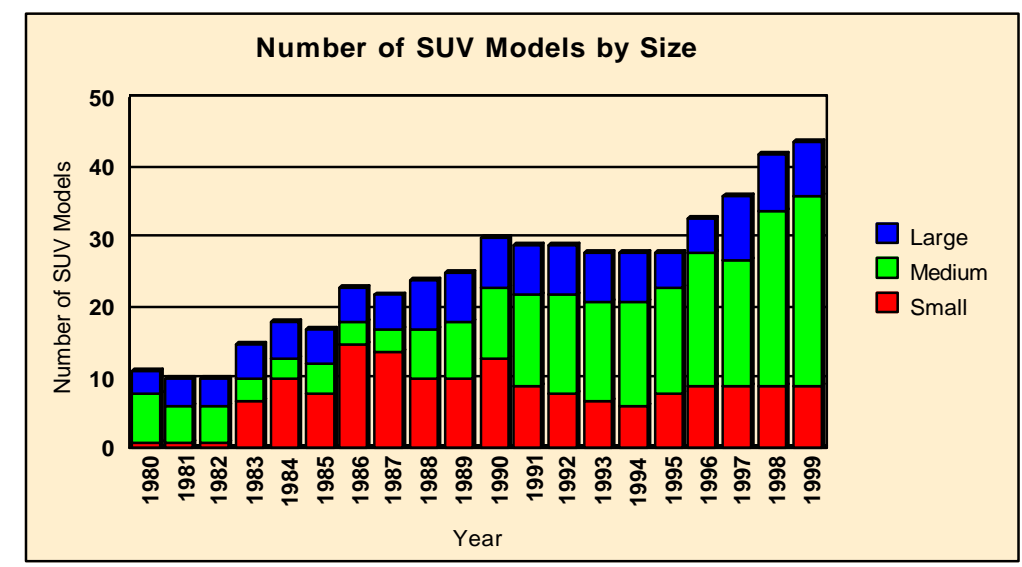

Figure 3. Number of SUV Models by Engine Size for Model Years 1980 through 1999. Source: Oak Ridge National Laboratory, Light Vehicle MPG and Market Shares System. 
Sales of SUVs have grown from slightly over 243 thousand units in 1980 to over 3 million units in 1999. Figure 4 compares the market shares of sales of SUVs with sales of other new light vehicles from 1980 through 1999. Sales of minivans, pickups, and vans (including all vehicles with gross vehicle weight ratings less than 8,500 pounds) and SUVs (all sizes) grew from about $20 \%$ of the market in 1980 to almost half in 1999. In the 1990s, strong SUV sales, combined with an increase of minivan, pickup, and van sales, caused quite a decline in market share for cars.

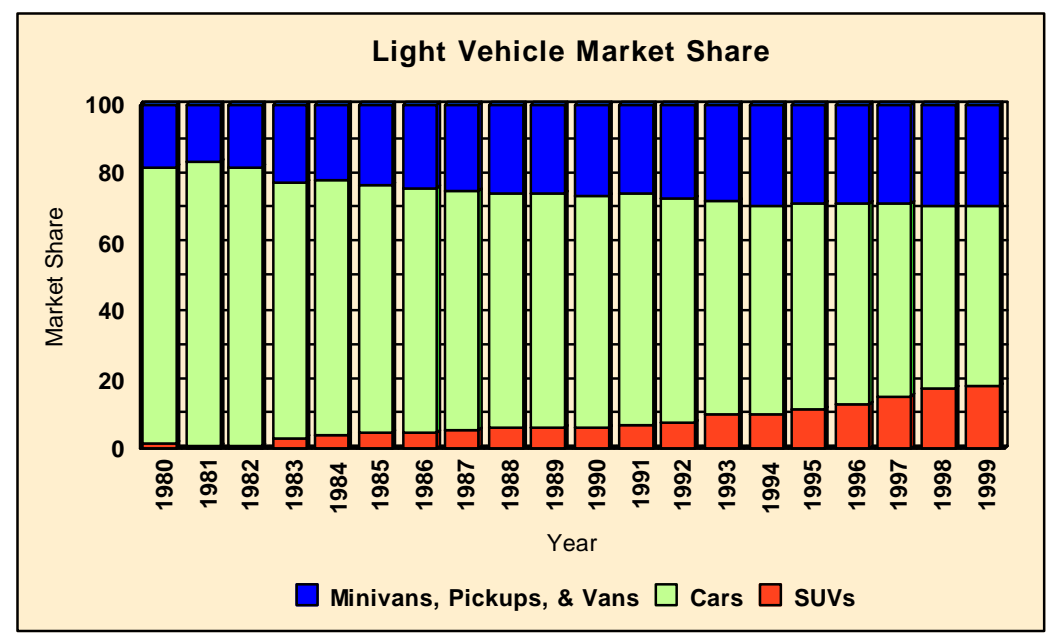

Figure 4. Market Shares of Sales of SUVs in Comparison with Sales of Other Light Vehicles, 1980-1999. Source: Oak Ridge National Laboratory, Light Vehicle MPG and Market Shares System.

Based on these charts, it would appear that SUV sales could be expected to increase dramatically in the next few years unless something occurs to change the market trend (e.g., a fuel shortage occurs). Polk estimates that SUV sales will be about $23 \%$ of the light vehicle market from $2001-2005 .{ }^{5}$ According to AutoPacific's The US Car and Light Truck Market, sales of SUVs are projected to be over 3 million units annually throughout the next decade with the fastest growing SUV category that of medium-sized SUVs. ${ }^{6}$ (See Table 1 for nameplates.)

Figure 5 compares projected sales of SUVs from 2000 through 2003 with other vehicle types. The entire market is forecast to rise abou t $4.5 \%$ during that time period. The small car (the most energy-efficient vehicle) market share is projected to decrease

\footnotetext{
${ }^{5}$ The Polk Company, "Sport Utility Owners Keep Coming Back for More," http://www.polk.com/pressreleases/20000119.pdf.

${ }^{6}$ AutoPacific, The US Car and Light Truck Market, 1999, pp. 119-20.
} 
slightly. While luxury cars, pickup trucks, and SUVs will all show gains in their market shares, the greatest gains will be for SUVs. ${ }^{7}$

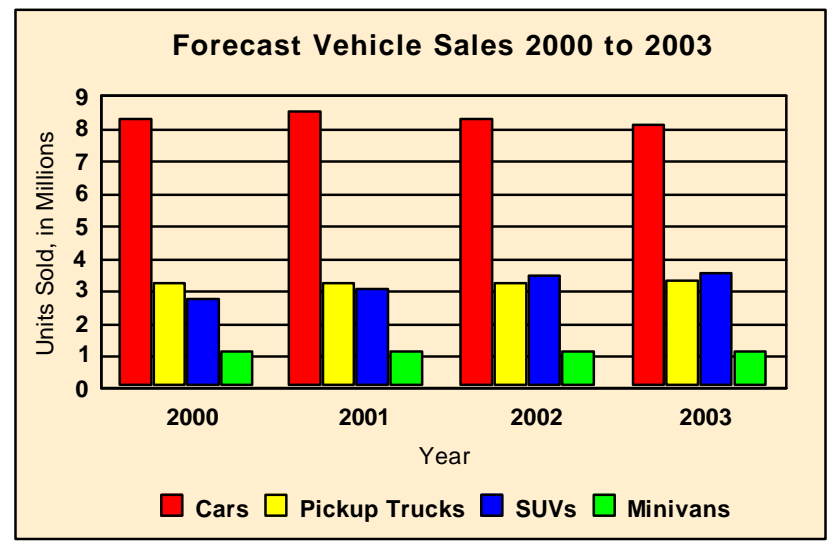

Figure 5. Forecast Sales of Light Vehicles Through the Year 2003 Source: AutoPacific, The US Car and Light Truck Market, 1999, pp. 24, 120, 121.

\section{ECONOMIC FACTORS AND MOBILITY TRENDS}

Many articles have been written about SUVs being road hog s and gas guzzlers. In addition, they are not budget-priced. Profits on automobiles are quite slim in comparison with profit margins on SUVs. ${ }^{8}$ When the economy is booming, however, the ticket price is not always the deciding factor. ${ }^{9}$

The gross domestic product since 1980 is shown in Figure 6 in constant 1996 dollars. As shown in this figure, the United States is producing more and continues a trend of slow but steady growth.

\footnotetext{
${ }^{7}$ AutoPacific, The US Car and Light Truck Market, 1999, p. 119.

${ }^{8}$ Office of Transportation Technologies, http://www.ott.doe.gov/facts/archives/fotw111.html, "Fact of the Week," Fact \#111, January 3, 2000. (Original source: J.D. Power and Associates.)

${ }^{9}$ Bradsher, Keith, "The Unsung Comeback of the Large Car," The New York Times, October 3, 1999.
} 


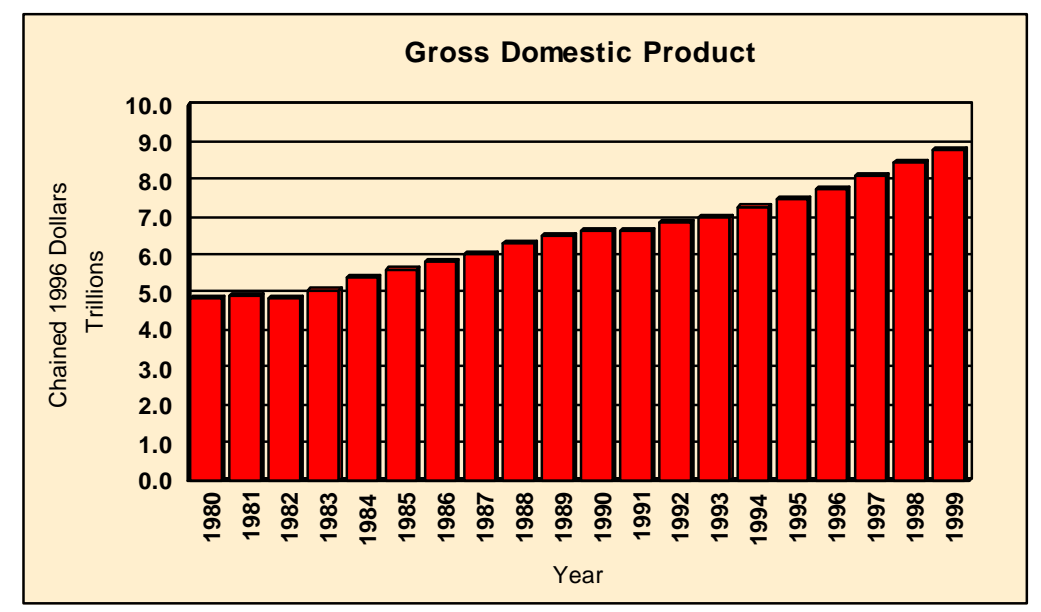

Figure 6. Gross Domestic Product (constant 1996 dollars) as a Masure of Economic Growth. Source: Bureau of Economic Analysis web site, "National Income and Product Accounts," http://www.bea.doc.gov/bea/dn/gdplev.htm.

Figure 7 shows the economic condition in the United States as measured by the median household income in both current and constant dollars. Although household income has grown in terms of current dollars, the real growth has been cyclical and at a slow rate (in terms of constant dollars). In the 1990s, real growth of household income has shown a steady increase (from \$33,922 in 1993 to $\$ 37,718$ in 1998 in constant 1996 dollars).

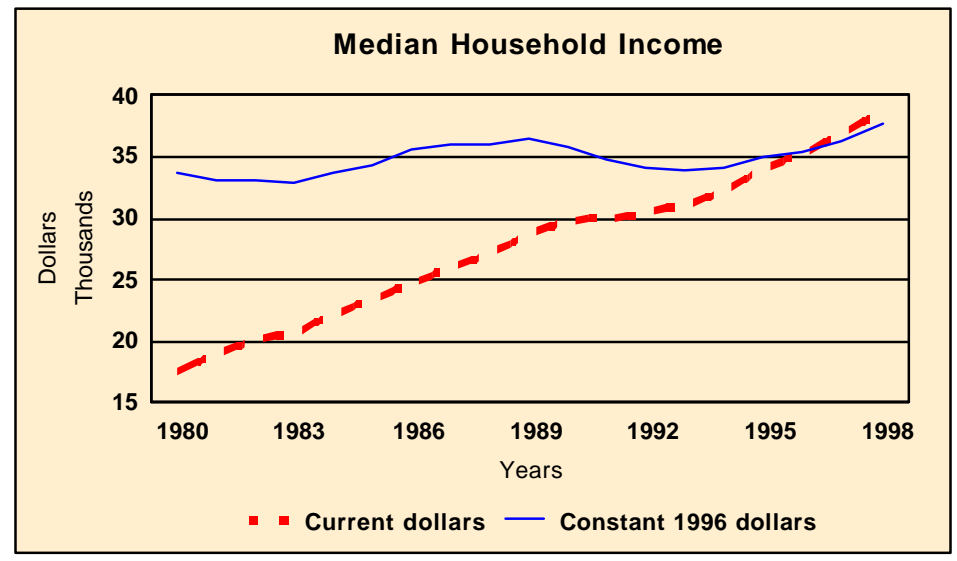

Figure 7. Median Household Income, in Current and Constant 1996 Dollars, since 1980. Source: U.S. Bureau of the Census, Statistical Abstract of the United States, Section 14, Table No. 739, http://www.census.gov/prod/3/98pubs/98statab/sasec14.pdf. 
As shown in Figures 6 and 7, productivit y and income have shown growth. In addition to steady real growth in household income during the 1990s, personal income per capita increased from $\$ 20,652$ in 1990 to $\$ 22,713$ in 1997 (in constant 1992 dollars). ${ }^{10}$

Since 1980, automotive technologies have imp roved and the passenger vehicle has become safer ${ }^{11}$ and more comfortable. As highways were built, widened, and improved, fuel prices increased very little in comparison with the general economy. Figure 8 shows the average prices of fuel since 1980 in const ant dollars. Fuel prices have been rather low in recent years compared to the early 80s. This graph, however, does not show the increase in fuel prices in early 2000. Since 1990, the percentages of average annual household expenditures which consumers s pend on vehicle purchases and fuel have remained fairly constant at about $10-11 \%$ of all consumer expenditures ( $7-8 \%$ for vehicle purchases and $3-3.5 \%$ for fuel costs). ${ }^{12}$

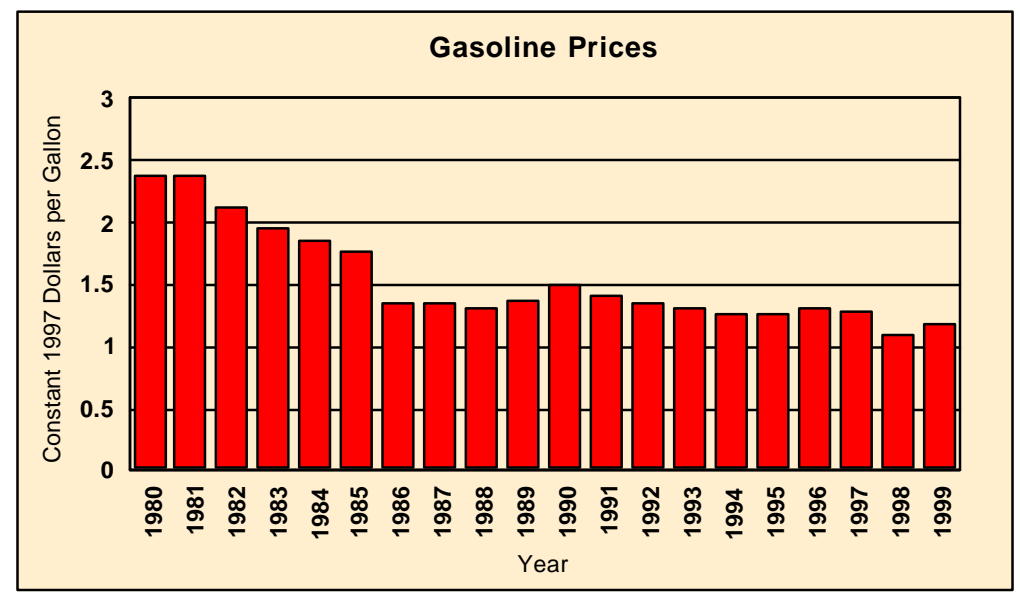

Figure 8. Average Gasoline Prices Per Gallon Since 1980 in Constant 1997 DHars. Source: U.S. Department of Energy, Energy Information Administration, Monthly Energy Review, February 2000, Table 9.4.

\footnotetext{
${ }^{10}$ U.S. Bureau of the Census, Statistical Abstract of the United States, Section 14, Table No. 727, http://www.census.gov/prod/3/98pubs/98statab/sasec14.pdf.

${ }^{11}$ Just in the past decade, the fatality rate, as measured in fatalities per 100 million vehicle miles traveled, decreased from 2.3 (in 1988) to 1.6 (in 1998). Source: U.S. Department of Transportation, National Highway Traffic Safety Administratio n, http://www.nhtsa.dot.gov/people/ncsa/pdf/Overview98.pdf. ${ }_{12}$ Davis, Stacy C., Transportation Energy Data Book, Ed. 19, ORNL-6958, September 1999, Table 11.2; additional data of fuel an d vehicle costs from Transportation Energy Data Book, Eds. 9-19.
} 
A good economy, improved roads, and low fuel prices contributed to greater mobility of the average American citizen. Between 1983 and 1990, the average daily vehicle trips per household increased by almost 15\%; between 1990 and 1995, the average daily vehicle trips per household increased by another $12 \%{ }^{13}$ The average annual person miles traveled (PMT) from 1983 to 1990 and from 1990 to 1995 increased by $9 \%$ and $14 \%$, respectively. ${ }^{14}$ Each year, the total vehicle miles traveled (VMT) in the United States increases; these increases have been at a rate of around 3\% annually throughout the 1990s. Higher population, more vehicles register ed, increased PMT, and increased VMT indicate that transportation activity is continuing to grow. Figure 9 shows increases in VMT/vehicle since 1980. Although the average annual VMT/vehicle has not increased at the same rate as overall VMT, it has certai nly not seen any decreases.

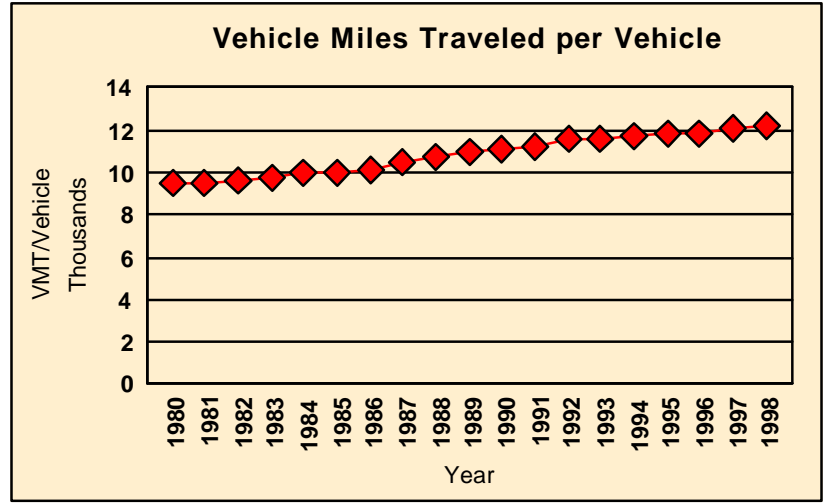

Figure 9. Average Annual Vehicle DistanceTraveled per Vehicle Since 1980. Source: U.S. Department of Transportation, Federal Highway Administration, Highway Statistics Summary to 1995 (Table VM-201A), Highway Statistics 1996 (Table VM-1); Highway Statistics 1997 (Table VM-1) and Highway Statistics 1998 (Table VM-1), http://www.fhwa.dot.gov/ohim/ohimstat.htm.

The economy is holding steady. Although U.S. citizens travel more and go further every year, expenditures for vehicles and fuel remain at approximately the same share of the household income as in the past.

\footnotetext{
${ }^{13}$ Hu, P. S., and Young, J. R., Summary of Travel Trends: 1995 Nationwide Personal Transportation Survey. Table 2.

${ }^{14}$ Davis, Stacy C., Transportation Energy Data Book. Ed. 19. Table 11.7.
} 


\section{SUVS AND THEIR BUYERS/DRIVERS}

To understand the success of the SUV and to project the level of int erest in SUVs in the near future, we examine typical profiles of both the vehicles and their owners.

\subsection{VEHICLE CHARACTERISTICS}

Generally speaking, SUVs are described as being large, sturdy, high -priced, appropriate for hauling/towing, safe (to the SUV occupants), and "trendy." In terms of size, the small SUV category (dominated by the Honda CR-V and the Toyota RAV4) allows buyers to purchase the SUV image without paying a huge price. Base model prices range from almost $\$ 14,000$ to $\$ 23,000$ (see Table 1). The sales-weighted average price for a small SUV in 1999 was $\$ 17,833$.

The middle SUV category (led by the Ford Explorer, Jeep Grand Cherokee, Chevrolet Blazer, Jeep Cherokee, and Toyota 4Runner) has the largest number of nameplates as well as the greatest sales. Base model prices range from under $\$ 15,000$ to over $\$ 66,000$ (Table 1). The sales -weighted average price for a medium SUV in 1999 was $\$ 28,754$.

The large SUV category (including the Ford Expedition, Chevrolet Tahoe, Dodge Durango, and Chevrolet Suburban) has larger engines but not necessarily larger price tags than SUVs in the middle category. Base model prices for vehicles with significant sales range from under $\$ 25,000$ to almost $\$ 46,500$ (Table 1). The sales -weighted average price for a large SUV in 1999 was $\$ 30,538$.

Small SUVs have fuel economies similar to that of cars but the additional height, weight, and power requirements of the medium and large SUVs cause them to be less fuel efficient than cars. The sales -weighted fuel economies of new light vehicles in 1999 indicate that the large SUVs are, on average, the least fuel -efficient type of light vehicle (Figure 10). 


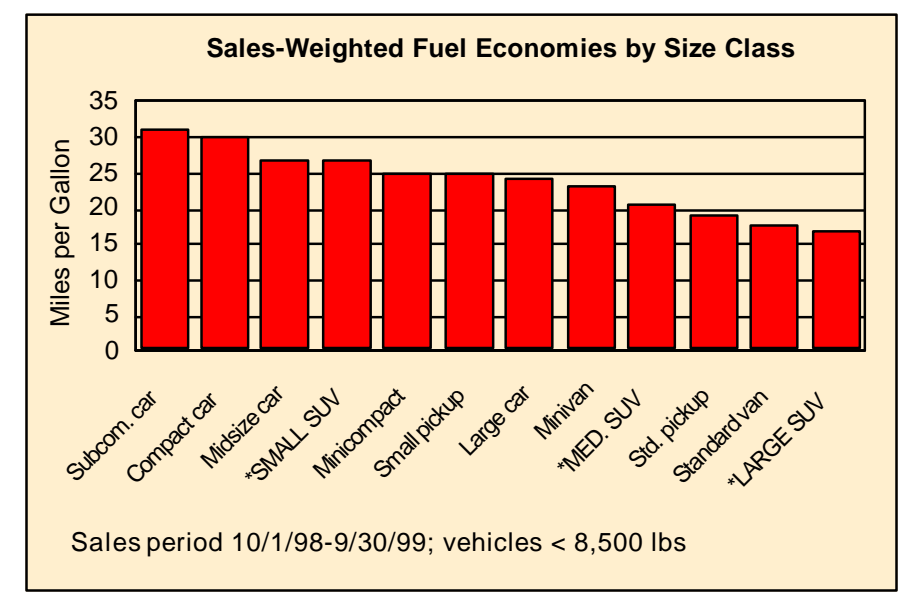

Figure 10. Sales-Weighted Fuel Economies by Vehicle Size Class, for Vehicles Weighing 8,500 Pounds or Less; SalesPeriod Covers 10/1/98 Through 9/30/99. Source: Oak Ridge National Laboratory, Light Vehicle MPG and Market Shares System.

Because SUVs are currently categorized as light trucks, they are required to meet Federal fuel economy and emissions standards for light trucks. Corporate Average Fuel Economy (CAFE) standards for light trucks are less stringent than for cars. For example, the CAFE standard for automobiles is currently $27.5 \mathrm{mpg}$, while it is only $20.7 \mathrm{mpg}$ for light trucks. ${ }^{15}$ The purpose of these relaxed fuel economy requirements for light trucks is to benefit small businesses that use trucks in their businesses - for example, to haul materials or products. ${ }^{16}$ These days, however, most SUVs (84\%) and pickup trucks $(73 \%)$ are being used mainly for personal transportation. ${ }^{17}$

As more and more people switch from cars to less fuel-efficient SUVs, the United States as a whole will increase its oil demand to fuel these vehicles. Table 2 shows an average annual fuel use for each vehicle size class. Large SUVs, on average, use $65 \%$ more fuel than large cars use in one year. Currently, more than half of our oil is imported, ${ }^{18}$ leaving the U.S. dependent on oil-rich OPEC nations.

\footnotetext{
${ }^{15}$ Davis, Stacy C., Transportation Energy Data Book, Ed. 19, Table 7.15.

${ }^{16}$ Niemeier, Deb, et al., "Redefining Conventional Wisdom: An Exploration of Auto Ownership and Travel Behavior in the U.S.," http://www.fhwa.dot.gov/ohim/travelconf/niemeier.pdf, p. 1.

${ }^{17}$ U.S. Bureau of the Census, 1997Economic Census, Vehicle Inventory and Use Survey, Microdata File, CD-ED97-VIUS.

${ }^{18}$ Davis, Stacy C., Transportation Energy Data Book, Ed. 19, Table 1.9.
} 
Table 2. Estimated Annual Fuel Use (Gallons) by Size Class

\begin{tabular}{lc|lc}
\hline \multicolumn{1}{c}{ Automobiles } & Annual fuel use & \multicolumn{1}{c}{ Light trucks } & Annual fuel use \\
\hline Subcompact car & 382 & Small pickup & 492 \\
Compact car & 389 & Small SUV & 507 \\
Midsize car & 446 & Minivan & 612 \\
Minicompact & 470 & Std. pickup & 632 \\
Large car & 487 & Medium SUV & 682 \\
& & Standard van & 783 \\
Weighted average & 428 & Large SUV & 801 \\
\hline
\end{tabular}

${ }^{a}$ Based on annual miles of 11,988 for all automobile classes; 14,256 for minivans and standard vans; 13,853 for all SUV classes; and 12,064 for all pickup classes.

Source: Average annual miles from Table 5 divided by fuel economies from Figure 10.

Because the cost of fuel in the United States has traditionally been fairly low, fuel economy is not as important to U.S. consumers as it is to consumers in Europe or Asia. In a survey conducted by AutoPacific in 1998, 30\% of all new car buyers considered fuel economy to be "extremely important"; however, only $18 \%$ of SUV buyers considered fuel economy as "extremely important," and only $10 \%$ rated the fuel economy of their new SUV as "excellent." The same survey noted that SUV owners expected a fuel economy of only $19 \mathrm{mpg}$ and that it would take a $70 \%$ increase in the price of fuel for them to change their vehicle type. ${ }^{19}$ Another national survey, which was not aimed specifically at new car buyers but the population in general, indicated that less than $5 \%$ of the survey respondents rated fuel economy as "most important in the choice of the next vehicle they purchased." ${ }^{20}$ Because of the rising fuel prices in early 2000 , the number of people ranking fuel economy as important may increase in future surveys. ${ }^{21}$ Possibly in anticipation of this occurrence, Ford and General Motors recently announced intentions of improving SUV fuel economies in the next few years.

The 1999 Green Guide to Cars and Trucks assigned "green" scores to vehicles based on fuel economy and emissions of pollutants. The only SUV to receive a

\footnotetext{
${ }_{19}$ AutoPacific, The US Car and Light Truck Market, 1999, pp. 167-174.

${ }^{20}$ Office of Transportation Technologies, http://www.ott.doe.gov/facts/archives/fotw56.html, "Fact of the Week," Fact \#56, February 26, 1998. (Original source: Opinion Research Corporation.)

${ }^{21}$ Check the Office of Transportation Technologies Facts and Analysis website for future opinion surveys, http://www.ott.doe.gov/facts.html.
} 
"superior" rating and be named as one of the 12 greenest vehicles in 1999 was the small Toyota RAV4 electric vehicle. Five SUVs (nine different nameplates) were named to the list of "12 Worst Vehicles for the Environment in 1999." Although the Ford Expedition is on the "12 Worst" list, the two-wheel-drive, 4.6-liter Expedition was named a "Best of '99" choice as one of the greener large SUVs. ${ }^{22}$

Federal emission standards for automobiles and light trucks have varied over the years; generally, standards for trucks have been less stringent. Since 1995, Federal emission standards have been the same for cars and the smallest light trucks [up to 6,000 pounds gross vehicle weight rating (GVWR) and 3,750 pounds loaded vehicle weight $(\mathrm{LVW}){ }^{23}$ Light trucks with a GVWR over 6,001 pounds or a LVW over 3,750 pounds have less stringent emission standards than the smaller vehicles. ${ }^{24}$ All of the large SUVs, most of the medium SUVs, and a couple of the small SUVs fall in this category. So, from the start, most SUVs are allowed to emit more pollutants than cars. Then, as vehicles get older, the amount of pollution they produce increases. ${ }^{25}$ According to the Green Guide to Cars \& Trucks, the average new light truck pollutes $40 \%$ more than the new average car. Table 3 shows the difference between cars and light trucks in emissions of carbon dioxide (the most important greenhouse gas) and several criteria pollutants. This may change in the future because of the Environmental Protection Agency's Tier 2 Federal Emission Standards, which are scheduled to be phased in from 2004-2007. "This regulation marks the first time that SUVs and other light-duty trucks-even the largest passenger vehicles - are subject to the same national pollution standards as cars." 26

${ }_{22}^{22}$ DeCicco, John, and Thomas, Martin, Green Guide to Cars \& Trucks, Model Year 1999, pp. 26-27.

${ }^{23}$ See Table 1; LVW = curb weight plus 300 pounds.

${ }^{24}$ Davis, Stacy C., Transportation Energy Data Book, Ed. 19, Tables 4.16-4.20.

${ }^{25}$ U.S. Department of Energy, Fuel Economy Site, www.fueleconomy.gov.

${ }^{26}$ U.S. Environmental Protection Agency, Air and Radiation, Office of Transportation and Air Quality, EPA's Program for Cleaner Vehicles and Cleaner Gasoline, 1999. 
Table 3. Emissions from a Typical New Car and Light Truck (pounds of pollutant per year)

\begin{tabular}{lcrcc}
\hline \multicolumn{1}{c}{ Pollutant } & $\begin{array}{c}\text { Pollutant } \\
\text { type }^{\mathrm{b}}\end{array}$ & $\begin{array}{c}\text { Average } \\
\text { new car }\end{array}$ & $\begin{array}{c}\text { Average new } \\
\text { light truck }\end{array}$ & $\begin{array}{c}\text { Percentage } \\
\text { difference }\end{array}$ \\
\hline Carbon dioxide & GHG & 15,200 & 21,200 & $39.5 \%$ \\
Carbon monoxide & CP & 420 & 547 & $30.2 \%$ \\
Hydrocarbons & CP & 55 & 74 & $34.5 \%$ \\
Nitrogen oxides & CP & 50 & 83 & $66.0 \%$ \\
Particulate matter & CP & 2.7 & 3.3 & $22.2 \%$ \\
\hline
\end{tabular}

${ }^{a}$ Includes both tailpipe emissions and fuel-cycle emissions and assumes the vehicle is driven 15,000 miles per year.

${ }^{b} \mathrm{GHG}=$ greenhouse gas. $\mathrm{CP}=$ criteria pollutant.

Source: DeCicco, John, and Thomas, Martin, Green Guide to Cars \& Trucks, Model Year 1999, p. 93.

Although the large SUV image implies superior towing capabilities, recent towing capacity ratings indicate that SUV towing capacities are representative of the particular engine size as well as the frame design, vehicle weight, and specific add-on tow packages. ${ }^{27}$ For example, the smaller SUVs (Isuzu Amigo and Jeep Wrangler) have tow capacities similar to those of luxury cars. The larger SUVs have significantly higher tow ratings. Table 4 shows towing capacities for selected 1999 models.

Last, but not least, SUV advertisements (and even the vehicle names) suggest rugged, off-road, mountain-climbing capabilities as SUV characteristics. Bradsher, in an article in The New York Times, stated that few drivers actually take their SUVs off-road. "According to an internal memorandum, the Big Three found in a joint 1995 study that only $13 \%$ of sport utility vehicles were driven off-road." 28

\footnotetext{
${ }^{27}$ Trailer Life, http://trailerlife.com/towratings/tr_index.cfm.

${ }^{28}$ Bradsher, Keith, "Deadly Crashes Increase Between Cars, Light Trucks," The New York Times, September 24, 1997.
} 
Table 4. Tow Ratings for Selected 1999 Models

\begin{tabular}{|c|c|c|}
\hline Nameplate & Engine; transmission & Tow limit ${ }^{a}$ \\
\hline \multicolumn{3}{|c|}{ Cars } \\
\hline Dodge Intrepid & All & 2,000 \\
\hline Ford Crown Victoria & $4.6, V-8$ & 2,000 \\
\hline Lincoln Continental Mark III & $4.6, V-8$ & 2,000 \\
\hline Mercury Grand Marquis & $4.6, \mathrm{~V}-8$ & 2,000 \\
\hline Cadillac (all) & $4.6, \mathrm{~V}-8$ & 3,000 \\
\hline Volvo & All & 3,300 \\
\hline \multicolumn{3}{|c|}{ Vans, Minivans } \\
\hline Oldsmobile Silhouette & $3.4, \mathrm{~V}-6$ & 2,000 \\
\hline Nissan Quest & $3.0, \mathrm{~V}-6$ & 3,500 \\
\hline Dodge Caravan & $3.3 / 3.8, \mathrm{~V}-6$ & 3,500 \\
\hline Plymouth Voyager & $3.3, \mathrm{~V}-6$ & 3,500 \\
\hline Volkswagen Eurovan & All & 4,400 \\
\hline \multicolumn{3}{|c|}{ Pickups } \\
\hline Chevrolet Silverado & 4.3, V-6, Manual & 3,500 \\
\hline Toyota Tacoma & all I-4 & 3,500 \\
\hline Dodge Dakota & 3.9, V-6, Manual & 4,400 \\
\hline Ford F 150 & 4.2, V-6, Auto & 5,800 \\
\hline Dodge Ram 1500 & 5.2/5.9, V-8, Auto & 8,000 \\
\hline \multicolumn{3}{|c|}{ SUVs } \\
\hline Isuzu Amigo & $3.2, \mathrm{~V}-6$ & 2,000 \\
\hline Jeep Wrangler & $4.0, \mathrm{I}-6$ & 2,000 \\
\hline Oldsmobile Bravada & $4.3, \mathrm{~V}-6$, Auto & 5,000 \\
\hline Chevrolet Blazer/GMC Jimmy & 4.3, V-6, Auto & 5,500 \\
\hline Mercury Mountaineer & $4.0, \mathrm{~V}-6$ & 5,860 \\
\hline Land Rover Range Rover & All & 6,500 \\
\hline Suburban C1500 & 5.7, V-8, Auto & 6,500 \\
\hline Ford Expedition (4WD) & 5.4, V-8, Auto & 6,800 \\
\hline Ford Expedition & 5.4, V-8, Auto & 8,300 \\
\hline Hummer (2 passenger) & Diesel & 8,510 \\
\hline
\end{tabular}

${ }^{a}$ For additional notes, requirements, and limitations, see specifications for each tow rating listed at Trailer Life,

http://trailerlife.com/towratings/tr index.cfm.

\subsection{BUYER/DRIVER PROFILES}

In the fall of 1998, AutoPacific surveyed 40,000 people to obtain information on the type of vehicle that purchasers/leasers were considering for their next purchase/lease. For those 30 years of age and under, $73 \%$ indicated that they were considering an SUV for their next purchase, as did $63 \%$ of survey participants in their 30 s and $50 \%$ of those in their 40s. For those 65 and older, only $13 \%$ were considering buying an SUV. Overall 
(i.e., all ages), $48 \%$ responded that they were considering an SUV. ${ }^{29}$ It is interesting to note that consumers currently in their 30s and early 40s would have been children and teenagers during the oil crisis of 1973-74 when families were urged to conserve energy and people were lining up for hours at the gas station in some parts of the country. Yet, some in this group seem to have lost the "energy conservation" mindset, as they are now ardent fans of SUVs.

The average SUV customer is male (63.7\%), married (76.4\%), aged 45 years, in a household with an income of $\$ 94,400$, and at the head of the household (84\%). SUV customers expect to drive 14,367 miles each year and 39\% are prior owners of another SUV. ${ }^{30}$ Because SUV owners are fairly affluent, the price of the vehicle and of fuel is not sufficiently important to cause them to consider changing the type of vehicle they drive.

Based on data from the 1995 Nationwide Personal Transportation Study (NPTS), Niemeier determined that $29.3 \%$ of total household vehicles (i.e., non-commercial vehicles) on the road are SUVs, vans, or trucks (most of these are pickup trucks), and only about a third of these vehicles are owned by persons with annual incomes under $\$ 35,000 .^{31}$

Although the primary SUV customer is male, women are beginning to enter the SUV market because of their perception that the SUV is safer and provides better visibility. This perception of safety is based on the size, shape, and rugged image of the vehicle, rather than published reports or statistics (see Section 5). In addition, soccer moms who drove minivans are changing their personna when they move from a minivan to a sport utility vehicle. It has been projected that $53.8 \%$ of future SUV buyers will be female. In the United States, women influence "as much as $80 \%$ of all vehicle buying decisions." 32

In early 1999, an opinion poll queried 1,000 consumers to determine the single most important reason for purchasing a particular type of vehicle. Owners of small cars responded with reasons such as price/value and fuel economy; owners of large cars

\footnotetext{
${ }^{29}$ Office of Transportation Technologies, http://www.ott.doe.gov/facts/archives/fotw92.html, "Fact of the Week," Fact \#92, June 8, 1999. (Original source: AutoPacific Group.)

${ }^{30}$ AutoPacific, The US Car and Light Truck Market, 1999, pp. 143-144.

${ }^{31}$ Niemeier, Deb, et al., "Redefining Conventional Wisdom: An Exploration of Auto Ownership and Travel Behavior in the U.S.," http://www.fhwa.dot.gov/ohim/travelconf/niemeier.pdf, Table 1-2.

${ }^{32}$ Maples, John D., et al., Vehicle Consumer Characteristics and Trends Data Book, pp. 54-55. (Original source: Dorhing National Survey.)
} 
indicated price/value and safety; owners of minivans indicated size of family and more space/room; and owners of pickups indicated price/value and hauling (as well as work/business). SUV owners responded that the primary reason for their purchase was availability of four-wheel-drive. Additionally, 5\% indicated hauling capabilities and another $5 \%$ noted towing as reasons for their purchase. ${ }^{33}$

Opinion polls taken in December 1996 and in February 1998 asked questions concerning the characteristics most desired in vehicles. In both polls, the most important characteristics were dependability and safety, and both of these characteristics were listed as even more important to consumers in 1998 than in 1996. In both polls, fuel economy and low price were the least important attributes, and they were listed as of lesser importance in 1998 than in $1996 .^{34}$

Owners of minivans and SUVs are more likely to have children than owners of any other automotive category. In addition, SUV buyers list "Family Vehicle," functionality, and reliability as the most desirable characteristics in a vehicle. ${ }^{35}$

SUV purchasers have been categorized by J. D. Powers as either "Domestic Indulgents" (those who buy a vehicle based on size, status, and luxury equipment) or "Utility Seekers" (those who buy for functionality - hauling, towing, room for more passengers, and safety). ${ }^{36}$

According to The Polk Company, the Babyboomer generation is leading the way in buying SUVs. The basic sedan was the vehicle of choice when the family only owned one car. The number of vehicles per household in the United States had grown to 1.9 in 1998, however, and now most households own one car and one truck. ${ }^{37}$

\footnotetext{
${ }_{33}$ Office of Transportation Technologies, http://www.ott.doe.gov/facts/archives/fotw83.html, "Fact of the Week," Fact \#83, March 29, 1999. (Original source: Opinion Research Corporation.)

${ }^{34}$ Office of Transportation Technologies, http://www.ott.doe.gov/facts/archives/fotw56.html, "Fact of the Week," Fact \#56, February 26, 1998. (Original source: Opinion Research Corporation.)

${ }^{35}$ The Polk Company, "Goodbye Family Car ... Hello Family Light Truck," http://www.polk.com/pressreleases/20000120.pdf.

${ }^{36}$ Maples, John D., et al., Vehicle Consumer Characteristics and Trends Data Book, p. 61. (Original source: J.D. Powers and Associates.)

${ }^{37}$ The Polk Company, "Do Current Truck Sales Predict the Death of the Car?" http://www.polk.com/pressreleases/19990921.pdf.
} 


\subsection{SUV USAGE AND TRAVEL}

The 1995 NPTS shows that SUVs travel more than automobiles on an annual basis (Table 5). In fact, SUVs traveled more than cars for each vehicle age category in the 1995 NPTS except those automobiles with a vehicle age of 16 years or greater. SUVs (all ages) were driven 13\% more than the average of all vehicles, and $16 \%$ more than automobiles, although they were driven $3 \%$ fewer miles than were vans.

Table 5. Average Annual Miles per Vehicle by Vehicle Type and Vehicle Age and Ratio of Vehicle Miles by Vehicle to Automobile Vehicle Miles

\begin{tabular}{|c|c|c|c|c|c|}
\hline \multirow{3}{*}{$\begin{array}{l}\text { Vehicle age } \\
\text { (years) }\end{array}$} & \multicolumn{4}{|c|}{ Vehicle type } & \multirow[b]{3}{*}{$\mathrm{All}^{b}$} \\
\hline & Automobile & $\operatorname{Van}^{a}$ & SUV & Pickup & \\
\hline & Miles & Miles (Ratio) & Miles (Ratio) & Miles (Ratio) & \\
\hline $0-5$ & 14,319 & $16,271(1.14)$ & $15,350(1.07)$ & 16,107 (1.12) & 14,901 \\
\hline $6-10$ & 12,044 & $13,095(1.09)$ & $13,979(1.16)$ & $12,305(1.02)$ & 12,280 \\
\hline $11-15$ & 9,771 & $11,693(1.20)$ & 10,985 (1.12) & $9,516(0.97)$ & 9,701 \\
\hline $16+$ & 6,407 & $8,392(1.31)$ & $5,919(0.92)$ & $6,604(1.03)$ & 6,381 \\
\hline Average (all ages) & 11,988 & $14,256(1.19)$ & $13,853(1.16)$ & $12,064(1.01)$ & 12,226 \\
\hline
\end{tabular}

${ }^{a}$ Includes minivans.

${ }^{b}$ Includes automobiles, vans, SUVs, pickup trucks, other personal trucks, motorcycles, recreational vehicles, and any other personal vehicle reported in NPTS.

Source: U.S. Department of Transportation, Federal Highway Administration, 1995 Nationwide Personal Transportation Survey, http://www-cta.ornl.gov/npts.

It has been suggested that driver characteristics could explain the high annual mileage of SUVs. The following observations were made using data from the 1995 NPTS. The information is based on data from the primary driver of the vehicle. If there was no primary driver of the vehicle or the primary driver of the vehicle was not interviewed, the data were not included in the analysis. It should be noted that driver data, as compiled by NPTS surveys, differs slightly from the buyer profiles provided by AutoPacific (Section 4.2).

\$ Sixty percent of those driving SUVs are male, while only $44 \%$ of those driving cars are male. The annual VMT of males is approximately $4 \%$ more than that of females.

$\$$ Thirty-eight percent of those driving SUVs have a family income of $\$ 40,000-$ $\$ 79,999$ as compared to $29 \%$ of car drivers. The annual VMT for drivers with a family income of $\$ 40,000$ - $\$ 79,999$ is approximately $13 \%$ higher than those drivers whose family income is less than $\$ 40,000$. 
\$ Fifty-two percent of those driving SUVs are in families which consist of more than one adult plus children; this compares to $38 \%$ of car drivers. The annual VMT for drivers with a family of more than one adult plus children is approximately $8 \%$ higher than the average for all families.

\$ The average age of an SUV driver is 40.2 years. This is the lowest average driver age of all vehicle types. The average age of a car driver is 44.1 years. Drivers between the ages of 26 to 35 have the highest annual VMT. (Age categories in the 1995 NPTS are ten-year increments beginning with 16 years of age.)

$\$$ Fifty percent of those driving SUVs have two vehicles in their household, while only $43 \%$ of those driving cars have two vehicles. The annual VMT for drivers with two vehicles in their household is approximately $4 \%$ higher than the average for all households with vehicles.

\$ Twenty percent of SUV drivers live in rural areas whereas $18 \%$ of car drivers live in rural areas. The annual VMT for all drivers living in rural areas is approximately $6 \%$ higher than the national average.

\$ Thirty-three percent of SUV drivers live in areas with a population density of 0 to 500 people per square mile as opposed to $27 \%$ of car drivers. The annual VMT for drivers in areas with a population density of 0 to 500 people is approximately $6 \%$ over the national average.

Using the NPTS, Niemeier et al. compared travel patterns in suburban/second city areas with those in urban areas. Suburban/second city households own $6.8 \%$ more passenger cars and $12.5 \%$ more vehicles in the SUV-van-truck category than do urban households. SUV-van-truck vehicles are used at about the same rate as automobiles for all trip purposes (i.e., work-related, shopping, family and household, social/recreational, etc.) and by both men and women. The NPTS is limited to households and does not include company fleet vehicles, which confirms that SUVs are being used for personal trips and are not being used exclusively in business endeavors. Because SUV emissions and fuel economy are regulated by truck standards, which are less stringent than automobile requirements, this apparent replacement of the family car with an SUV will have the effect of using more energy and emitting more tailpipe emissions than would have occurred with the typical automobile. ${ }^{38}$

\footnotetext{
${ }^{38}$ Niemeier, Deb, et al., "Redefining Conventional Wisdom: An Exploration of Auto Ownership and Travel Behavior in the U.S.," 1999, http://www.fhwa.dot.gov/ohim/travelconf/niemeier.pdf.
} 


\subsection{WHY BUY A SPORT UTILITY VEHICLE?}

As stated in earlier sections, the sales of SUVs have increased dramatically, especially during the past ten years. Many people are referring to the increase in SUV sales as a fad, based on the purchaser perception that they are fashionable and make a statement about an active or high-income lifestyle. (Actually, purchase costs vary widely from the economy versions to the luxury models, and the longevity of the SUV popularity makes it unlikely to be a fad.) Popularity of SUVs could also be encouraged by the relatively low fuel prices and good fuel availability in the U.S. and by the absence of public pressure to conserve energy or to control pollution. In addition, the United States economy is strong, and individuals have more money to spend on luxuries. Furthermore, because the SUV market is so good, almost every manufacturer offers at least one SUV option. Most recently the luxury sport utility hit the market, with sticker prices above $\$ 45,000$.

Advertising plays a major role in influencing purchasing decisions. In the Fall of 1999, Ford Motor Company started a new ad campaign for its suite of SUVs; the ads emphasize outdoor adventures, with "no boundaries." The image is what sells; the implication is that one could go anywhere in the SUV, if one weren't so busy commuting to work and running errands. ${ }^{39}$

Although image is important when making a vehicle purchase, the height of the SUV is also a factor. Market surveys show that "visibility from the driver's seat ties a vehicle's driving performance and interior comfort as the most important attributes that buyers seek." 40 Finally, SUV owners profess to feeling more protected and more in control of their safety in traffic when encased within an SUV. These perceptions and other safety issues are examined in the next section.

\section{SUVS AND SAFETY}

The public believes that SUVs are safer than cars because they are generally larger (considered a weight advantage in crashes with other vehicles), higher (improved

\footnotetext{
${ }^{39}$ Bradsher, Keith, “Advertising," The New York Times, August 23, 1999, p. C12.

${ }^{40}$ Bradsher, Keith, "The Unsung Comeback of the Large Car," The New York Times, October 3, 1999.
} 
visibility), and more rugged (a vehicle that can climb mountains and cross streams of water will surely be more than adequate on a city street). Recently, however, the Insurance Institute for Highway Safety, Consumers Union, and the National Highway Traffic Safety Administration (NHTSA) published reports that indicate SUVs are not as safe as they might appear to be.

Table 6 shows the number of fatalities from 1980 through 1998 for SUV-involved crashes in small, medium, and large SUV categories and compares these numbers with total highway fatalities. The numbers of SUV fatalities in this table are the sum of SUV occupants, occupants of non-SUV vehicles (when the crash involved an SUV), and nonmotorists. As shown in Table 6, the number of fatalities involving SUVs is increasing, as is the percentage of SUV-related fatalities over total fatalities. While the number of total highway fatalities fell from 51,091 in 1980 to 41,471 in 1998 (a reduction of 18.83\%), SUV-involved fatalities rose from 991 to 4,607, during the same time period.

Table 6. Fatalities in SUV-Involved Crashes, 1980-1998, by SUV Size Category

\begin{tabular}{lcrrrrrrrr}
\hline & Total & \multicolumn{8}{c}{ Crash fatalities, including all vehicle occupants and non-motorists } \\
\cline { 3 - 9 } Year & $\begin{array}{c}{ }^{a} \text { highway } \\
\text { fatalities }\end{array}$ & $\begin{array}{c}\text { Small } \\
\text { SUVs }\end{array}$ & $\begin{array}{c}\text { Percent } \\
\text { small }\end{array}$ & $\begin{array}{c}\text { Medium } \\
\text { SUVs }\end{array}$ & $\begin{array}{c}\text { Percent } \\
\text { medium }\end{array}$ & $\begin{array}{c}\text { Large } \\
\text { SUVs }\end{array}$ & $\begin{array}{c}\text { Percent } \\
\text { large }\end{array}$ & $\begin{array}{r}\text { Total } \\
\text { SUVs }\end{array}$ & $\begin{array}{r}\text { Percent } \\
\text { of total }\end{array}$ \\
\hline 1980 & 51,091 & 0 & $0.0 \%$ & 586 & $1.1 \%$ & 405 & $0.8 \%$ & 991 & $1.9 \%$ \\
1981 & 49,301 & 38 & $0.1 \%$ & 631 & $1.3 \%$ & 431 & $0.9 \%$ & 1,100 & $2.2 \%$ \\
1982 & 43,945 & 388 & $0.9 \%$ & 174 & $0.4 \%$ & 222 & $0.5 \%$ & 784 & $1.8 \%$ \\
1983 & 42,589 & 366 & $0.9 \%$ & 156 & $0.4 \%$ & 235 & $0.6 \%$ & 757 & $1.8 \%$ \\
1984 & 44,257 & 368 & $0.8 \%$ & 207 & $0.5 \%$ & 253 & $0.6 \%$ & 828 & $1.9 \%$ \\
1985 & 43,825 & 425 & $1.0 \%$ & 469 & $1.1 \%$ & 357 & $0.8 \%$ & 1,251 & $2.9 \%$ \\
1986 & 46,087 & 368 & $0.8 \%$ & 907 & $2.0 \%$ & 468 & $1.0 \%$ & 1,743 & $3.8 \%$ \\
1987 & 46,390 & 312 & $0.7 \%$ & 982 & $2.1 \%$ & 453 & $1.0 \%$ & 1,747 & $3.8 \%$ \\
1988 & 47,087 & 276 & $0.6 \%$ & 1,176 & $2.5 \%$ & 486 & $1.0 \%$ & 1,938 & $4.1 \%$ \\
1989 & 45,582 & 250 & $0.5 \%$ & 1,385 & $3.0 \%$ & 520 & $1.1 \%$ & 2,155 & $4.7 \%$ \\
1990 & 44,599 & 280 & $0.6 \%$ & 1,448 & $3.2 \%$ & 574 & $1.3 \%$ & 2,302 & $5.2 \%$ \\
1991 & 41,058 & 373 & $0.9 \%$ & 1,560 & $3.8 \%$ & 510 & $1.2 \%$ & 2,443 & $6.0 \%$ \\
1992 & 39,250 & 339 & $0.9 \%$ & 1,602 & $4.1 \%$ & 448 & $1.1 \%$ & 2,389 & $6.1 \%$ \\
1993 & 40,150 & 414 & $1.0 \%$ & 1,846 & $4.6 \%$ & 456 & $1.1 \%$ & 2,716 & $6.8 \%$ \\
1994 & 40,716 & 449 & $1.1 \%$ & 2,160 & $5.3 \%$ & 513 & $1.3 \%$ & 3,122 & $7.7 \%$ \\
1995 & 41,817 & 426 & $1.0 \%$ & 2,466 & $5.9 \%$ & 567 & $1.4 \%$ & 3,459 & $8.3 \%$ \\
1996 & 42,065 & 460 & $1.1 \%$ & 2,830 & $6.7 \%$ & 554 & $1.3 \%$ & 3,844 & $9.1 \%$ \\
1997 & 42,013 & 506 & $1.2 \%$ & 3,190 & $7.6 \%$ & 614 & $1.5 \%$ & 4,310 & $10.3 \%$ \\
1998 & 41,471 & 498 & $1.2 \%$ & 3,457 & $8.3 \%$ & 652 & $1.6 \%$ & 4,607 & $11.1 \%$ \\
\hline
\end{tabular}

${ }^{a}$ Percentages represent the percent of fatalities in a particular size category to total fatalities.

Source: National Highway Traffic Safety Administration, "Traffic Safety CD-ROM, Fatality Analysis Reporting System (FARS): 1975-1994, and General Estimates System (GES): 1988-1994," BTS-CD-10, Bureau of Transportation Statistics, U.S. Department of Transportation; also FARS On-Line Query System at http://wwwfars.nhtsa.dot.gov/www/query.html. 
While the total number of highway fatalities decreased by $7 \%$ between 1990 and 1998, the total SUV-related fatalities increased by almost 100\%. Figure 11 compares total highway fatalities and SUV-involved fatalities.

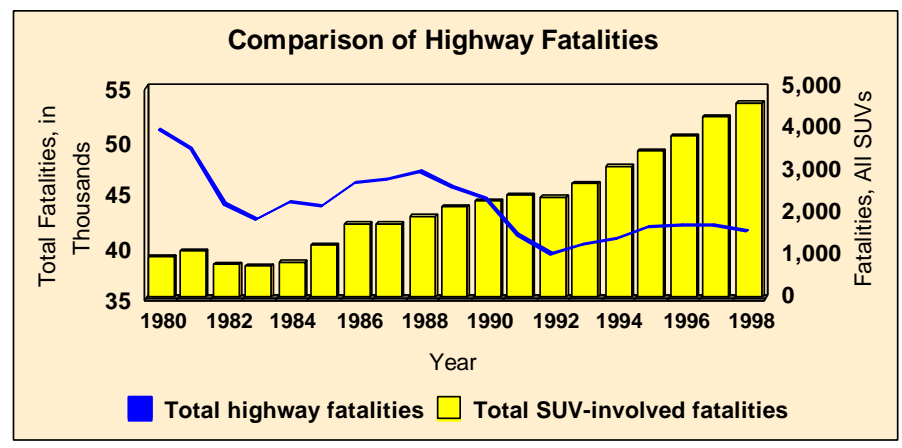

Figure 11. Comparison of Total Highway Fatalities (line; left axis) and SUV Involved Fatalities (bars; right axis). Source: National Highway Traffic Safety Administration, "Traffic Safety CD-ROM" and FARS On-Line Query System at http://wwwfars.nhtsa.dot.gov/www/query.html.

Though Figure 11 indicates that SUV-involved fatalities are increasing while overall fatalities are decreasing, it is important to note the change in the actual mix of vehicles on the road. There are many more SUVs on the roads today than there were in the 1980s, or even the early 1990s. Figure 12 compares the share of SUV registrations (over total registrations) and the share of SUV-involved fatalities (over all fatalities) between 1985 (the earliest registration data available to ORNL) and 1998 (the latest fatality data available from the Fatality Analysis Reporting System). As can be seen in this figure, the share of SUV fatalities is increasing but not faster than the increase in the share of SUVs on the road. 


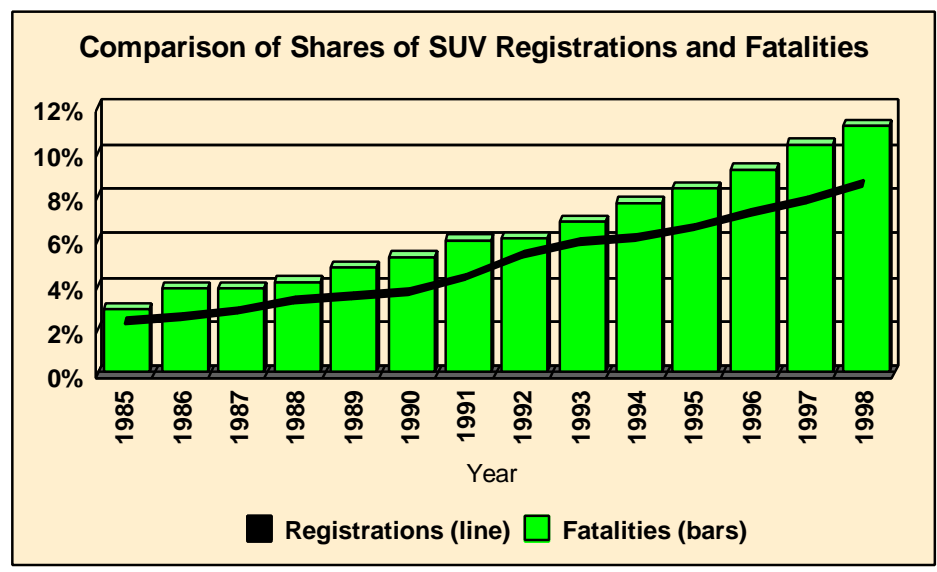

Figure 12. Comparison of the Share of SUV Registrations to Total Registrations (line) and the Share of SUVInvolved Fatalities to Total Fatalities (bars), 19851998. Source: The Polk Company, National Vehicle Population Profile 1985-1998, computer data files, and National Highway Traffic Safety Administration, "Traffic Safety CD-ROM" and FARS On-Line Query System at http://www-fars.nhtsa.dot.gov/www/query.html.

Figure 13 compares overall vehicle registrations with overall highway fatalities between 1985 and 1998. As seen in this figure, overall fatalities are decreasing even while the total number of vehicles registered continues to increase.

Based on a comparison of fatality data for SUVs to other vehicles, the registeredvehicle-fatality rate (defined as number of fatalities per number of registered vehicles) for SUVs is higher than the registered-vehicle-fatality rate for other vehicles. Figure 14 shows the fatality rates for all vehicles and for SUVs since 1985.

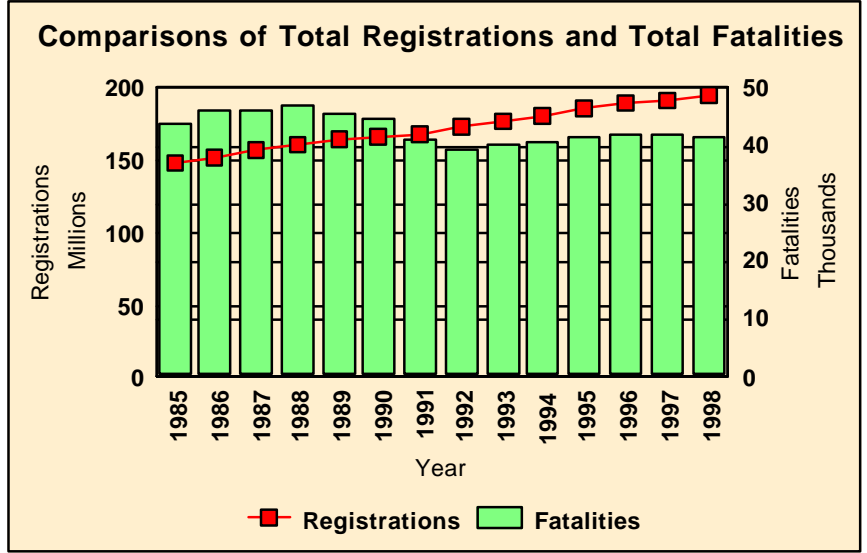

Figure 13. Comparison of the Number of Total Registrations of All Vehicle Stock (line) and the Number of Total Fatalities (bars), 19851998. Source: The Polk Company, National Vehicle Population Profile 1985-1998, computer data files, and National Highway Traffic Safety Administration, “Traffic Safety CD-ROM” and FARS On-Line Query System at http://www-fars.nhtsa.dot.gov/www/query.html. 


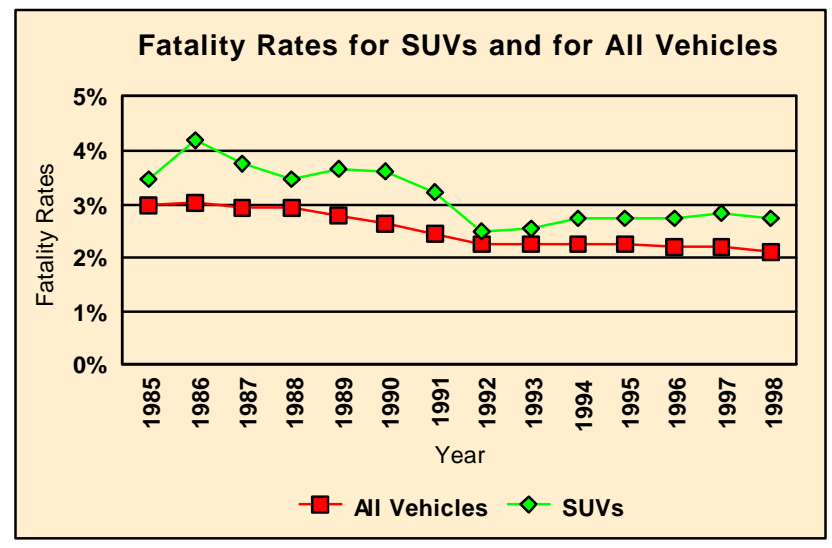

Figure 14. Fatality Rates for All Vehicles and for SUVs, Where Fatality Rate Is Defined as the Number of Fatalities per 100 Registered Vehicles.Source: The Polk Company, National Vehicle Population Profile 1985-1998, computer data files, and U.S. Department of Transportation, National Highway Traffic Safety Administration, "Traffic Safety CD-ROM" and FARS On-Line Query System at http://www-fars.nhtsa.dot.gov/www/query.html.

The Insurance Institute of Highway Safety has published some fatality/exposure comparisons by vehicle type and size. Table 7 shows fatality rates, where fatality rate is defined as number of fatalities per million registered passenger vehicles 1-3 years old. As shown in Table 7, the fatality rate is highest for small and very small cars, mediumsized pickups, and small SUVs. The fatality rate is lowest for occupants of SUVs weighing over 5,000 pounds. 
Table 7. Deaths per Million Passenger Vehicles 13 Years Old, 1998

\begin{tabular}{|c|c|c|c|c|}
\hline $\operatorname{Size}^{a}$ & $\begin{array}{l}\text { Cars (including } \\
\text { minivans) }\end{array}$ & $\begin{array}{l}\text { Pickups (4WD } \\
\text { only) }\end{array}$ & $\begin{array}{c}\text { SUVs } \\
\text { (4WD only) }\end{array}$ & $\begin{array}{c}\text { Size } \\
\text { explanations }^{b}\end{array}$ \\
\hline Very small & 245 & $\mathrm{n} / \mathrm{a}$ & $\mathrm{n} / \mathrm{a}$ & Car: $\mathrm{WB} \leq 100 ; \mathrm{L} \leq 165$ \\
\hline Small & 166 & $\mathrm{n} / \mathrm{a}$ & 186 & $\begin{array}{l}\text { Car: WB }=101-105 ; \mathrm{L}=166-180 \\
\text { SUV: weight }<3000 \mathrm{lbs}\end{array}$ \\
\hline Medium & 135 & 178 & 113 & $\begin{array}{l}\text { Car: WB }=106-110 ; \mathrm{L}=181-195 \\
\text { PU/SUV: weight } 3,000-3,999 \mathrm{lbs}\end{array}$ \\
\hline Large & 106 & 130 & 131 & $\begin{array}{l}\text { Car: WB }=111-115 ; \mathrm{L}=196-210 \\
\text { PU/SUV: weight } 4,000-4,999 \mathrm{lbs}\end{array}$ \\
\hline Very large & 107 & 154 & 93 & $\begin{array}{l}\text { Car: WB } \geq 115 ; \mathrm{L} \geq 210 \\
\text { PU/SUV: weight } \geq 5,000 \mathrm{lbs}\end{array}$ \\
\hline
\end{tabular}

${ }^{a}$ It should be noted that the definitions of "size" are not the same for the different types of vehicles in these categories. Size is defined in terms of wheelbase and length for cars and in terms of weight for pickups and SUVs. The designations into size categories are approximate and, for SUVs, are not precisely as defined in Table 1. "n/a" indicates that there are no vehicles in a category.

${ }^{b}$ In these size explanations, "WB" = wheelbase in inches, and "L" = length of vehicle in inches; PU stands for pickup.

Source: Insurance Institute for Highway Safety, "Fatality Facts," http://www.highwaysafety.org/safety facts/fatality facts/passveh.htm.

It would be interesting to compare fatality rates over time for small, medium, and large SUVs. This comparison is not possible due to the lack of historical registration data by SUV category. However, historical SUV sales data are available for small, medium, and large SUVs. Appendix A shows that the growth in SUV registrations for all size categories closely parallels the growth in total SUV sales over time. After noting this similarity, Appendix A then compares sales and fatalities between 1980 and 1998 for small, medium, and large SUV size categories.

An overall "safety" factor, when defined as vehicle crashworthiness (occupant protection in a crash), is difficult to compute. There are various crash tests for head-on, frontal offset, side impact, and rollover tests, but there is no comprehensive scale to weight results from different types of tests. Although crash statistics indicate that large vehicles provide more protection than small vehicles in crashes, there is no methodology to compare crash test results across vehicle models in different size categories. ${ }^{41}$

${ }^{41}$ Wald, Matthew L. "Crash Test Statistics a Mystery to Buyers," The New York Times, February 21, 1997. 
Actually, crash test results are followed by a caution that the ratings are valid only for vehicles of approximately the same weight.

Safety concerns related to SUVs fall into two categories: (1) occupants of the SUV and (2) non-occupants of the SUV in multiple-vehicle and non-motorist crashes involving an SUV. Appendix B is a tabular listing of the number of fatalities from 1980 through 1998 for SUV-involved crashes of certain types. This appendix contains the total number of fatalities for both single-vehicle and multiple-vehicle crashes and lists the number of fatalities of SUV occupants and occupants of the other vehicle in multiplevehicle crashes. Appendix B also provides specific data for SUVs involved in rollover crashes that result in fatalities.

Occupants of SUVs are in greater danger of rollover crashes than are automobile occupants. SUVs tend to roll over more easily than automobiles or minivans because of their high centers of gravity, greater weight, and offroad tires, all of which hinder maneuverability. ${ }^{42}$ Figure 15 shows the proportion of rollover/non-rollover fatalities for small, medium, and large SUVs involved in single-vehicle crashes from 1980-1998. Fatalities from rollover crashes were $22 \%$ of all fatalities from $1980-1998 .^{43}$ Singlevehicle crashes made up $56 \%$ of total fatal crashes in $1998 .^{44}$

Small SUVs are more likely to roll over than are medium and large SUVs. ${ }^{45}$ As shown in Figure 15 (see also Appendix B), almost 81\% of all small SUV, single-vehicle fatalities result from rollover crashes. "The single-vehicle rollover death rate in these vehicles in 1998 was more than 5 times as high as the rate in the largest cars (110 deaths per million registered vehicles compared with 22)."46 Not only are SUVs more likely to

\footnotetext{
${ }^{42}$ Bradsher, Keith, "The Unsung Comeback of the Large Car," The New York Times, October 3, 1999.

${ }^{43}$ U.S. Department of Transportation, National Highway Traffic Safety Administration, "Traffic Safety CD-ROM"

${ }^{44}$ U.S. Department of Transportation, National Highway Traffic Safety Administration, Traffic Safety Facts 1998, October 1999, p. 49.

${ }^{45}$ Consumers Union. "The Risk of Rollover in Some Sport-Utility Vehicles and Consumer Union's Testing for Such Risks," http://www.consumer.org/products/SUV/index.html.

${ }^{46}$ Insurance Institute for Highway Safety, "Fatality Facts," http://www.highwaysafety.org/safety_facts/fatality/facts/passveh.htm.
} 


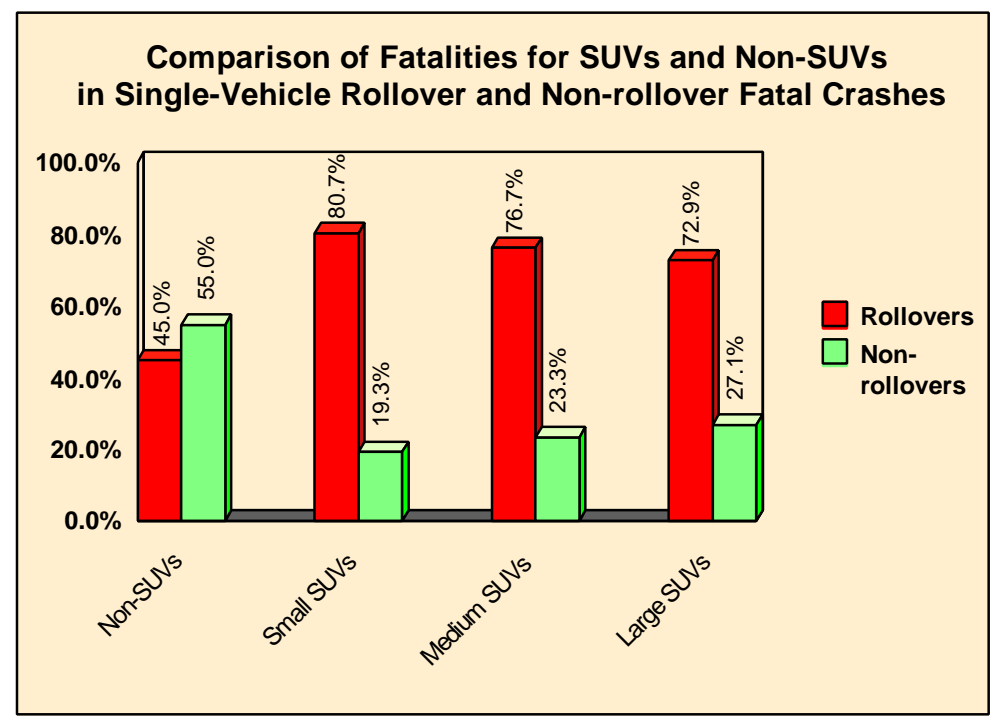

Figure 15. Comparison of Fatalities for SUVs and NonSUVs in Single-Vehicle Rollover and Non-rollover Fatal Crashes. Source: U.S. Department of Transportation, National Highway Traffic Safety Administration, "Traffic Safety CD-ROM" and FARS On-Line Query System at http://www-fars.nhtsa.dot.gov/www/query.html.

tip and to roll over than are non-SUVs, their construction does not provide the same protection as does that of automobiles. ${ }^{47}$ The proportion of rollover fatalities for occupants of non-SUV vehicles involved in single-vehicle crashes from 1980 through 1998 is much lower (only about 45\%) than that of small SUVs.

Receiving its support from various automobile insurance companies, the Insurance Institute for Highway Safety evaluates crashworthiness (i.e., how well a vehicle protects occupants in a crash). Table 8 lists the results of crash tests for various makes and models within several categories. According to the Insurance Institute of America, frontal offset crash tests are the principal component for judging crashworthiness. In this type of crash test, the medium SUV has better ratings than the mid-sized car.

\footnotetext{
47 “The SUV Info Link," http://www.suv.org/safety.html.
} 
Table 8. Crashworthiness Evaluations: Frontal Offset Crash Test Performance

\begin{tabular}{lccccc}
\hline \multirow{2}{*}{ Category } & $\begin{array}{c}\text { Number } \\
\text { tested }^{a}\end{array}$ & Good & Acceptable & Marginal & Poor \\
\cline { 3 - 6 } Small cars & 16 & 1 & 11 & 2 & 2 \\
Small SUVs & 10 & 1 & 4 & 4 & 1 \\
Small pickups & 8 & 0 & 3 & 3 & 2 \\
Passenger vans & 13 & 3 & 0 & 3 & 7 \\
Midsize 4-door cars & 15 & 3 & 5 & 0 & 7 \\
Medium SUVs & 15 & 3 & 5 & 3 & 4 \\
Large family cars & 11 & 4 & 3 & 2 & 2 \\
Large luxury cars & 8 & 5 & 2 & 1 & 0 \\
\hline
\end{tabular}

${ }^{a}$ Tests of earlier designs are not included in the count of vehicle models tested.

Source: Insurance Institute for Highway Safety, "Vehicle Ratings,"

http://www.highwaysafety.org/vehicle ratings/ratings.htm.

Figure 16 compares the number of fatalities of SUV occupants to the number of fatalities of occupants of the other vehicle in multiple-vehicle crashes involving SUVs (see also Appendix B). In multiple-vehicle crashes involving small SUVs, more SUV occupants are fatally injured than occupants of the other vehicle. For multiple-vehicle crashes of medium and large SUVs, the non-SUV occupants are more often fatalities. To see the numbers of non-motorists fatally injured in encounters with SUVs, see the tabular listing in Appendix B.

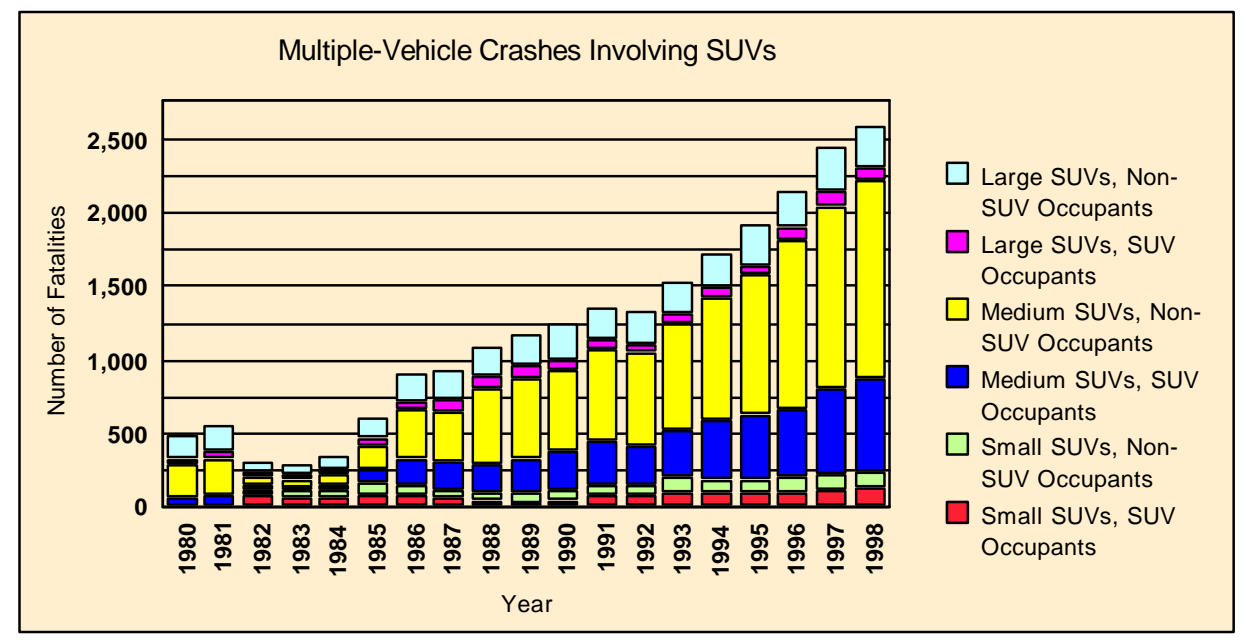

Figure 16. Number of Fatalities for MultipleVehicle Crashes Involving SUVs, 1980 . 1998, by SUV Size and by SUV Occupant/Nonoccupant Status. Source: U.S. Department of Transportation, National Highway Traffic Safety Administration, "Traffic Safety CD-ROM" and FARS On-Line Query System at http://www-fars.nhtsa.dot.gov/www/query.html. 
As shown in Figure 16, medium and large SUVs pose a potential threat to occupants of other vehicles in crashes, just as any other heavy vehicle would. As the size of the SUV increases, the danger to occupants of the "other" vehicle increases. In collisions with medium-sized SUVs, occupants of the non-SUV suffer twice as many fatalities; in collisions with large SUVs, occupants of the non-SUV suffer three times as many fatalities.

Because the bumper and frame on medium and large SUVs are higher than on cars, the SUV may override the bumpers on a car in a collision, causing more intrusion into the automobile. Side impacts are even more hazardous for the automobile occupants than are frontal crashes. In multi-vehicle crashes, when a car is struck by an SUV in a side-impact collision, the occupants of the car are "27 times more likely to die." ${ }^{48}$ These dangers are brought on by the SUV's added weight, height, and rigid frame design.

In 1997, some insurance companies raised their rates for liability insurance covering SUVs to account for the excessive damage SUVs caused to cars in collisions. (It should be noted that collision rates for insuring SUVs are generally lower than automobile rates, which implies that the overall cost to insure an SUV could be less than the cost to insure a similar-priced automobile with insurance companies that do not adjust the liability premiums.) ${ }^{49}$

\section{CONCLUSIONS}

This study analyzed the growth in popularity of SUVs and examined the impact of SUVs on energy consumption, air quality, and highway safety. The SUV market in the 1990s has seen an increase in the number of available models as well as expanding sales. Since 1990, growth has been greatest for the medium-sized SUV category. It should be noted that while the market for SUVs has grown rapidly, so has the entire lighttruck market share. In addition, sales of SUVs, as well as light trucks, are projected to continue to increase between 2000 and 2003.

\footnotetext{
48 "The SUV Info Link," http://www.suv.org/safety.html.

${ }^{49}$ Bradsher, Keith. "Some Insurers to Increase Rates for Large Vehicles," The New York Times, October 17, 1997.
} 
Several possible reasons have been suggested to explain the popularity of SUVs:

- a sign of economic wellbeing - the percentage of total household expenditures for vehicle purchases and fuel costs has remained almost constant, as the available income has increased in the 1990s,

- a perception of safety - the size of the vehicle and its greater visibility give a perception of safety, and

- "utility" - the average U.S. citizen is more mobile than ever; the SUV combines the hauling/towing power of a pickup truck with the roominess and seating capacity of a minivan.

Though many have called the rising popularity of SUVs a "fad," with over 16 million registered SUVs (over 3 million sold in 1999 alone - 19\% of all light vehicle sales), the SUV is going to be very visible on our highways for years. If the economy takes a down swing or fuel prices increase substantially, sales may begin to stabilize or decline. The popularity of SUVs, however, is not based on vehicle price or fuel economy but on the sporty, rugged image of the vehicle and a perception of safety when encased within its sturdy frame. These reasons for purchasing an SUV are not likely to change. Therefore, SUV popularity will almost certainly continue at the forecast rate (over 3 million units annually after 2000).

Except for those in the small-size category, SUVs generally use more fuel (see Figure 10) and emit more pollutants (see Table 3) than automobiles. In addition, because SUV owners drive more miles per year than the average automobile owner, these additional fuel uses and pollutant emissions are compounded. As shown in Table 2, small SUVs use more fuel annually than large cars; therefore, the popularity of SUVs increases the nation's dependency on imported oil and comes at a cost to the environment.

As the number of SUVs on the highways grows, the fatal crashes involving SUVs also increases, particularly the medium SUVs, which are the best sellers. In 1998, Polk data indicated that $8.7 \%$ of light vehicles were SUVs. During this same year, $11.1 \%$ of all fatalities were in crashes that involved SUVs. The fatality rate for SUVs is higher than that of non-SUVs. Does this mean that SUVs are dangerous? No one can say for sure. Usually, larger, heavier vehicles protect their passengers in crashes better than smaller, lighter vehicles. Therefore, larger, heavier SUVs may have safety advantages (for their occupants) when compared to smaller, lighter vehicles. Smaller SUVs would 
not have the same advantage. And there are certainly concerns about SUV rollovers. Small SUVs are involved in more single-vehicle rollover fatalities than non-SUVs. Purchasing decisions, however, will most often be made by whether the buyer feels safe in the vehicle, instead of using hard facts and crash test data which are difficult to interpret. The safety of these vehicles, therefore, may simply be in the eye of the beholder.

What does the future hold? As new models are developed, their fuel economy may improve, as may their emissions controls. Manufacturers of small, economy cars will develop marketing strategies that will emphasize the advantages of smaller vehicles to a particular market. Some may realize that 4 -wheel-drive is not a necessity on city streets. But the SUV will continue as a significant player in the personal vehicle industry and will continue to be useful as a station wagon/minivan/pickup truck/all-terrain vehicle - rolled into one. 


\section{REFERENCES}

AutoPacific. The US Car and Light Truck Market, FT Automotive, Financial Times Business Ltd., London, 1999.

Bradsher, Keith. “Advertising," The New York Times, p. C12, August 23, 1999.

Bradsher, Keith. "Deadly Crashes Increase Between Cars, Light Trucks," The New York Times, September 24, 1997.

Bradsher, Keith. "Some Insurers to Increase Rates for Large Vehicles," The New York Times, October 17, 1997.

Bradsher, Keith. "The Unsung Comeback of the Large Car," The New York Times, Section 3, pp. 7-9, October 3, 1999.

Bureau of Economic Analysis. "National Income and Product Accounts," http://www.bea.doc.gov/bea/dn/gdplev.htm.

Consumers Union. "The Risk of Rollover in Some Sport-Utility Vehicles and Consumer Union's Testing for Such Risks," http://www.consumer.org/products/SUV/index.html.

Crain Communications. Automotive News: '99 Market Data Book. Detroit MI, May 1999.

Davis, Stacy C. Transportation Energy Data Book. Ed. 19. ORNL-6958. Oak Ridge National Laboratory, Oak Ridge, TN. September 1999.

DeCicco, John, and Thomas, Martin. Green Guide to Cars \& Trucks, Model Year 1999. American Council for an Energy-Efficient Economy, Washington, D.C., 1999.

Hu, P. S., and Young, J. R. Summary of Travel Trends: 1995 Nationwide Personal Transportation Survey. January 1999.

Insurance Institute for Highway Safety. "Fatality Facts," http://www.highwaysafety.org/safety facts/fatality facts/passveh.htm.

Insurance Institute for Highway Safety. "Vehicle Ratings," http://www.highwaysafety.org/vehicle ratings/ratings.htm.

Krebs, Michelle. "Vehicles So Much Alike They're Actually the Same," The New York Times, October 20, 1999. 
Maples, John D., Moore, James S., Jr., Patterson, Philip D., and Schaper, Vincent D. Vehicle Consumer Characteristics and Trends Data Book (Preliminary Draft), U.S. Department of Energy, Office of Transportation Technologies, August 1998. (Original source: pp. 54-55, Dorhing National Survey. p. 61, J.D. Powers and Associates.)

Niemeier, Deb, Redmond, Lorien, Morey, Jennifer, Hicks, Jamie, Hendren, Patricia, Erin, Jie Lin, Foresman, Zheng, Yi. "Redefining Conventional Wisdom: An Exploration of Auto Ownership and Travel Behavior in the U.S.," http://www.fhwa.dot.gov/ohim/travelconf/niemeier.pdf, September 1999.

Oak Ridge National Laboratory. Light Vehicle MPG and Market Shares System, Oak Ridge, TN, 1999. (Additional resources: http://www-cta.ornl.gov).

Office of Transportation Technologies. http://www.ott.doe.gov/facts/archives/fotw56.html, "Fact of the Week," Fact \#56, February 26, 1998. (Original source: Opinion Research Corporation.)

Office of Transportation Technologies. http://www.ott.doe.gov/facts/archives/fotw83.html, "Fact of the Week," Fact \#83, March 29, 1999. (Original source: Opinion Research Corporation.)

Office of Transportation Technologies. http://www.ott.doe.gov/facts/archives/fotw87.html, "Fact of the Week," Fact \#87, May 4, 1999. (Original source: 1995 Nationwide Personal Transportation Survey.)

Office of Transportation Technologies. http://www.ott.doe.gov/facts/archives/fotw92.html, "Fact of the Week," Fact \#92, June 8, 1999. (Original source: AutoPacific Group.)

Office of Transportation Technologies. http://www.ott.doe.gov/facts/archives/fotw111.html, "Fact of the Week," Fact \#111, January 3, 2000. (Original source: J.D. Power and Associates.)

The Polk Company. National Vehicle Population Profile 1985-1998, computer data files.

The Polk Company. "Do Current Truck Sales Predict the Death of the Car?" http://www.polk.com/pressreleases/19990921.pdf.

The Polk Company. "Goodbye Family Car ... Hello Family Light Truck," http://www.polk.com/pressreleases/20000120.pdf.

The Polk Company. "Sport Utility Owners Keep Coming Back for More," http://www.polk.com/pressreleases/20000119.pdf. 
"The SUV Info Link." http://www.suv.org/safety.html.

Trailer Life, http://trailerlife.com/towratings/tr_index.cfm.

U.S. Bureau of the Census. 1997 Economic Census, Vehicle Inventory and Use, Microdata File, CD-ED97-VIUS, January 2000.

U.S. Bureau of the Census. Statistical Abstract of the United States, Section 14, http://www.census.gov/prod/3/98pubs/98statab/sasec14.pdf.

U.S. Department of Energy, Energy Information Administration. Monthly Energy Review, February 2000, Table 9.4.

U.S. Department of Energy and Environmental Protection Agency. Model Year 2000 Fuel Economy Guide. http://www.fueleconomy.gov/feg/FEG2000.htm.

U. S. Department of Labor, Bureau of Labor Statistics. http://www.labor.org/workplace/charts/unemployment.html.

U.S. Department of Transportation, Federal Highway Administration, Office of Highway Information Management. Highway Statistics Summary to 1995. FHWA-PL-97009, July 1997.

U.S. Department of Transportation, Federal Highway Administration, Office of Highway Information Management. Highway Statistics 1996, Highway Statistics 1997, and Highway Statistics 1998, http://www.fhwa.dot.gov/ohim/ohimstat.htm.

U.S. Department of Transportation, Federal Highway Administration. 1995 Nationwide Personal Transportation Survey, http://www-cta.ornl.gov/npts).

U.S. Department of Transportation, National Highway Traffic Safety Administration. "Traffic Safety CD-ROM, Fatality Analysis Reporting System (FARS): 19751994, and General Estimates System (GES): 1988-1994," BTS-CD-10, Bureau of Transportation Statistics, U.S. Department of Transportation; also FARS On-Line Query System at http://www-fars.nhtsa.dot.gov/www/query.html.

U.S. Department of Transportation, National Highway Traffic Safety Administration. Traffic Safety Facts 1998, DOT HS 808 983, October 1999, http://www.nhtsa.dot.gov/people/ncsa/tsf-1998.pdf.

U.S. Department of Transportation, National Highway Traffic Safety Administration. Traffic Safety Facts 1998 Overview, DOT HS 808 956, http://www.nhtsa.dot.gov/people/ncsa/pdf/Overview98.pdf. 
U.S. Environmental Protection Agency, Air and Radiation, Office of Transportation and Air Quality. EPA's Program for Cleaner Vehicles and Cleaner Gasoline, EPA420-F-99-051, December 1999, http://www.epa.gov/oms/regs/ld-hwy/tier-2/frm/f99051.htm.

Wald, Matthew L. "Crash Test Statistics a Mystery to Buyers," The New York Times, February 21, 1997.

Ward's Communications. Ward's Automotive Yearbook. $61^{\text {st }}$ Ed., Southfield, MI, 1999. 


\section{Appendix A \\ Comparison of Fatality and Sales Data for SUVs}

The Polk Company collects registration data on light vehicles. The SUV share of light vehicle registrations as determined by data from Polk is given in Figure A-1. Figure A1 also shows the percentage of market share of SUV sales. The number of SUV registrations by size category as defined in this paper is not available. As demonstrated in Figure A-1, the percentage of registered vehicles that are SUVs has steadily increased since 1985, reaching $8.6 \%$ of total registrations in 1998, a year in which $17.7 \%$ of all light vehicles sold were SUVs. The growth of the number of SUVs on the highway, as represented by vehicle registrations, follows fairly closely the slope of the graph of the total sales of SUVs. From 1985 to 1998, the average annual growth in SUV registrations was $12.6 \%$ and in SUV sales was $10.8 \%$.

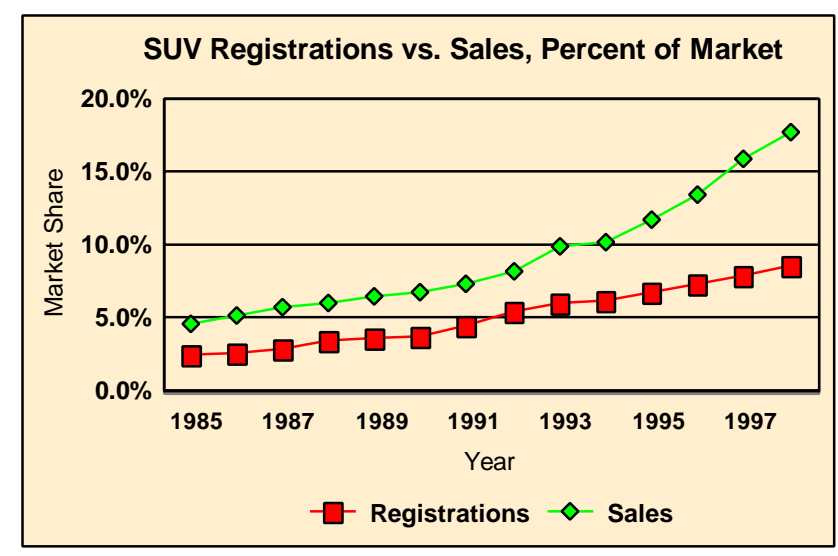

Figure A-1. Comparison of SUV Registrations with SUV Sales, 1985-1998, as a Percentage of Market Share. Source: The Polk Company, National Vehicle Population Profile 1985-1998, computer data files, and Oak Ridge National Laboratory, Light Vehicle MPG and Market Shares System.

Figure A-2 compares total SUV sales (all size categories) to SUV-involved fatalities from 1980 through 1998. This graph shows that fatalities increase as overall sales increase. 


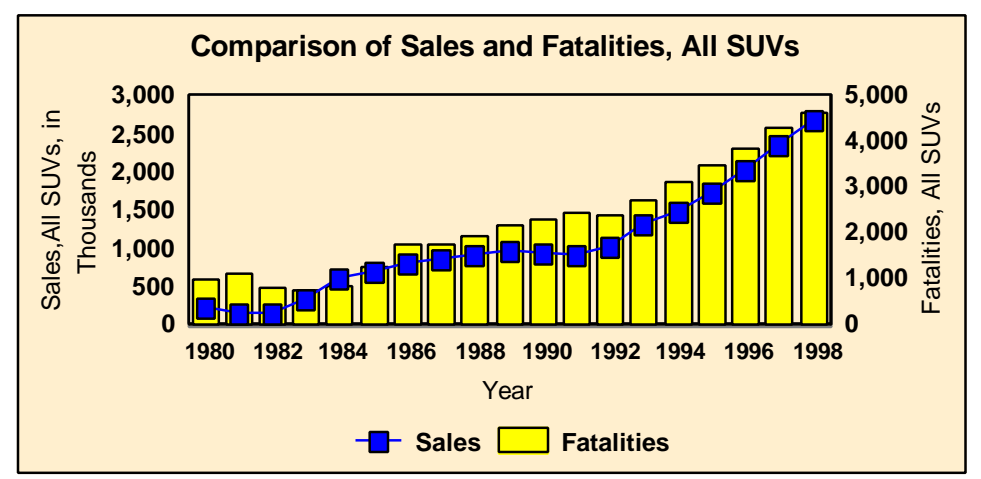

Figure A-2. Comparison of Sales of All SUVs (line; left axis) and SUV-Involved Fatalities (bars; right axis) for All SUV Size Categories. Source: National Highway Traffic Safety Administration, "Traffic Safety CD-ROM" and FARS On-Line Query System at http://wwwfars.nhtsa.dot.gov/www/query.html ; also Oak Ridge National Laboratory, Light Vehicle MPG and Market Shares System.

Using sales data as a measure of actual highway exposure is not completely legitimate because a single year of sales does not represent the total mix of vehicles on the highways. Using annual vehicle registration numbers would be a more accurate representation; however, data specifically showing SUV registrations over time by size categories are difficult to derive.

Because of the data limitations for obtaining registration data by size category and because overall market-share sales data are comparable to overall market-share registration data (Figure A-1), the next three charts use sales data, which are available by size categories, as a surrogate for registration data. These charts compare sales and fatalities since 1980 for SUVs by size category.

Figure A-3 compares sales of small SUVs and fatalities involving small SUVs. While the sales of small SUVs have fluctuated widely over the years, the total fatalities involving small SUVs have not followed the sales pattern. In the 1990s, the number of highway fatalities involving small SUVs has risen but has remained at around $1 \%$ of total highway fatalities. 


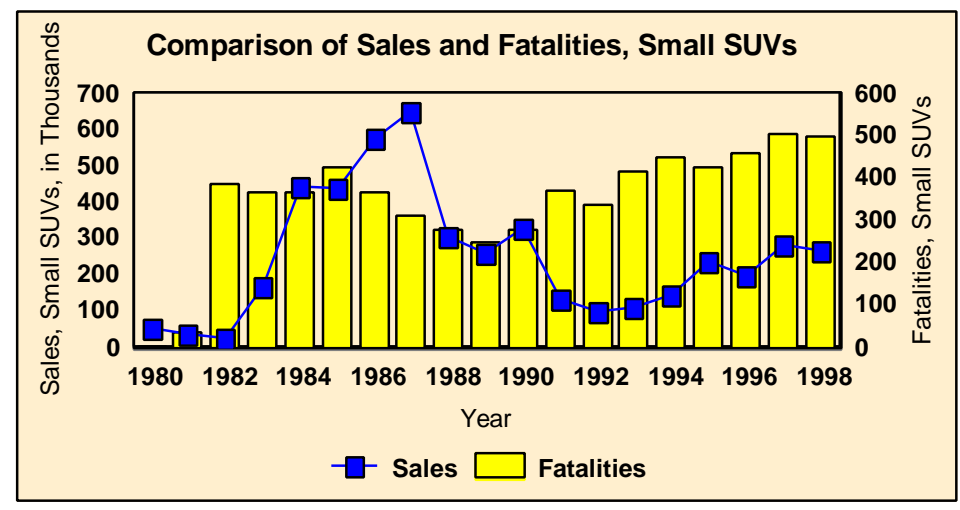

Figure A-3. Comparison of Sales of Small SUVs (line; left axis) and Fatalities Involving Small SUVs (bars; right axis) from 1980 through 1998. Sources: National Highway Traffic Safety Administration, "Traffic Safety CD-ROM" and FARS On-Line Query System at http://wwwfars.nhtsa.dot.gov/www/query.html; also Oak Ridge National Laboratory, Light Vehicle MPG and Market Shares System.

There was a dramatic increase in SUV occupant deaths (including both single-vehicle and multiple-vehicle crashes) between 1990 and 1998 for small and medium SUVs. Although the number of SUV occupant fatalities for large SUVs increased only $13 \%$ between these years, occupant fatalities for small and medium SUVs increased by $96 \%$ and $130 \%$, respectively. The greatest increase in number of fatalities was in the medium-sized SUV category. These increases in the number of SUV-involved fatalities followed increases in sales. When the sales of medium-sized SUVs increased dramatically, so did their highway exposure and their potential for being involved in crashes (Figure A-4).

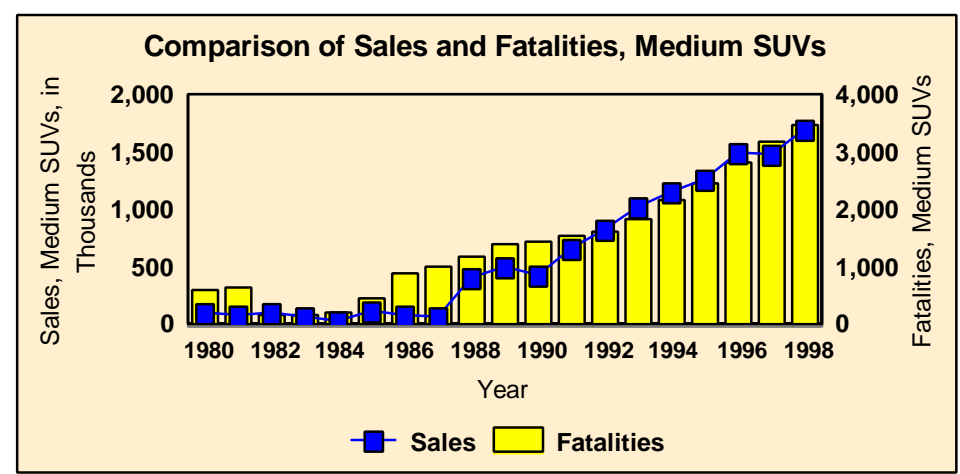

Figure A-4. Comparison of Sales of Medium SUVs (line; left axis) and Fatalities Involving Medium SUVs (bars; right axis) from 1980 through 1998. Sources: National Highway Traffic Safety Administration, "Traffic Safety CD-ROM" and FARS On-Line Query System at http://www-fars.nhtsa.dot.gov/www/query.html; also Oak Ridge National Laboratory, Light Vehicle MPG and Market Shares System. 
Large SUVs have maintained a fairly constant popularity, as measured in sales volume, since the mid-1980s. As shown in Figure A-5, sales of large SUVs increased dramatically in the mid- to late-1990s. Fatalities involving large SUVs remained at around $1 \%$ of total highway fatalities until the mid-1990s; they rose to $1.6 \%$ in 1998 .

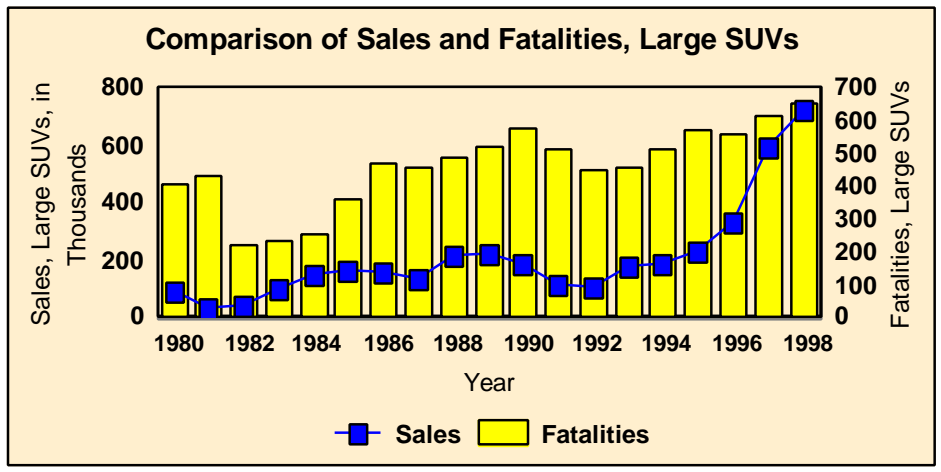

Figure A-5. Comparison of Sales of Large SUVs (line; left axis) and Fatalities (bars; right axis) from 1980 through 1998. Sources: National Highway Traffic Safety Administration, “Traffic Safety CD-ROM" and FARS On-Line Query System at http://wwwfars.nhtsa.dot.gov/www/query.html; also Oak Ridge National Laboratory, Light Vehicle MPG and Market Shares System

It must be noted that the charts contained in this appendix are based on sales data, not the actual numbers of SUVs on the road. 


\section{Appendix B}

\section{Number of Fatalities, by Year and Type of Accident, in Crashes Involving SUVs, by Size Category}

\begin{tabular}{|c|c|c|c|c|c|c|}
\hline Year & $\begin{array}{c}\text { Single-vehicle } \\
\text { crash, SUV } \\
\text { occupants }\end{array}$ & $\begin{array}{l}\text { Multiple- } \\
\text { vehicle } \\
\text { crash, SUV } \\
\text { occupants } \\
\end{array}$ & $\begin{array}{c}\text { Rollover } \\
\text { crashes: } \\
\text { Single-vehicle } \\
\text { crash, SUV } \\
\text { occupants } \\
\end{array}$ & $\begin{array}{c}\text { Rollover } \\
\text { crashes: } \\
\text { Multiple- } \\
\text { vehicles, SUV } \\
\text { occupants } \\
\end{array}$ & $\begin{array}{c}\text { Multiple- } \\
\text { vehicle crash, } \\
\text { occupants of } \\
\text { non-SUV } \\
\text { vehicle }\end{array}$ & $\begin{array}{c}\text { Non-motorist } \\
\text { fatalities } \\
\text { involving } \\
\text { SUV and non- } \\
\text { motorist } \\
\end{array}$ \\
\hline \multicolumn{7}{|c|}{ Small SUVs } \\
\hline 1980 & 0 & 0 & 0 & 0 & 0 & 0 \\
\hline 1981 & 28 & 3 & 25 & 0 & 5 & 2 \\
\hline 1982 & 248 & 74 & 210 & 42 & 45 & 21 \\
\hline 1983 & 243 & 67 & 199 & 25 & 40 & 16 \\
\hline 1984 & 219 & 66 & 179 & 22 & 53 & 30 \\
\hline 1985 & 233 & 81 & 194 & 26 & 83 & 28 \\
\hline 1986 & 192 & 79 & 155 & 24 & 72 & 25 \\
\hline 1987 & 169 & 58 & 136 & 26 & 65 & 20 \\
\hline 1988 & 160 & 39 & 126 & 16 & 59 & 18 \\
\hline 1989 & 137 & 33 & 118 & 10 & 64 & 16 \\
\hline 1990 & 129 & 49 & 110 & 14 & 74 & 28 \\
\hline 1991 & 191 & 86 & 151 & 31 & 67 & 29 \\
\hline 1992 & 159 & 80 & 124 & 37 & 72 & 28 \\
\hline 1993 & 168 & 103 & 135 & 29 & 96 & 47 \\
\hline 1994 & 215 & 90 & 166 & 37 & 103 & 41 \\
\hline 1995 & 205 & 103 & 155 & 36 & 83 & 35 \\
\hline 1996 & 222 & 97 & 187 & 38 & 100 & 41 \\
\hline 1997 & 232 & 110 & 172 & 38 & 119 & 45 \\
\hline 1998 & 218 & 131 & 175 & 42 & 110 & 39 \\
\hline \multicolumn{7}{|c|}{ Medium SUVs } \\
\hline 1980 & 246 & 61 & 181 & 18 & 228 & 51 \\
\hline 1981 & 252 & 70 & 191 & 23 & 245 & 64 \\
\hline 1982 & 63 & 29 & 44 & 5 & 60 & 22 \\
\hline 1983 & 59 & 24 & 46 & 5 & 55 & 18 \\
\hline 1984 & 91 & 36 & 76 & 7 & 62 & 18 \\
\hline 1985 & 181 & 87 & 144 & 26 & 162 & 39 \\
\hline 1986 & 320 & 167 & 247 & 61 & 342 & 78 \\
\hline 1987 & 363 & 189 & 290 & 62 & 339 & 91 \\
\hline 1988 & 357 & 201 & 265 & 61 & 506 & 112 \\
\hline 1989 & 467 & 233 & 360 & 65 & 550 & 135 \\
\hline 1990 & 523 & 263 & 400 & 92 & 533 & 129 \\
\hline 1991 & 513 & 293 & 384 & 98 & 612 & 142 \\
\hline 1992 & 544 & 259 & 415 & 89 & 635 & 164 \\
\hline 1993 & 621 & 316 & 480 & 109 & 720 & 189 \\
\hline 1994 & 717 & 406 & 520 & 137 & 817 & 220 \\
\hline 1995 & 837 & 435 & 632 & 151 & 948 & 246 \\
\hline 1996 & 946 & 468 & 746 & 153 & 1,149 & 267 \\
\hline 1997 & 1,023 & 568 & 810 & 199 & 1,242 & 357 \\
\hline 1998 & 1,173 & 635 & 895 & 240 & 1,334 & 315 \\
\hline
\end{tabular}




\begin{tabular}{|c|c|c|c|c|c|c|}
\hline Year & $\begin{array}{c}\text { Single-vehicle } \\
\text { crash, SUV } \\
\text { occupants }\end{array}$ & $\begin{array}{l}\text { Multiple- } \\
\text { vehicle } \\
\text { crash, SUV } \\
\text { occupants }\end{array}$ & $\begin{array}{c}\text { Rollover } \\
\text { crashes: } \\
\text { Single-vehicle } \\
\text { crash, SUV } \\
\text { occupants } \\
\end{array}$ & $\begin{array}{c}\text { Rollover } \\
\text { crashes: } \\
\text { Multiple- } \\
\text { vehicles, SUV } \\
\text { occupants } \\
\end{array}$ & $\begin{array}{c}\text { Multiple- } \\
\text { vehicle crash, } \\
\text { occupants of } \\
\text { non-SUV } \\
\text { vehicle } \\
\end{array}$ & $\begin{array}{c}\text { Non-motorist } \\
\text { fatalities } \\
\text { involving } \\
\text { SUV and non- } \\
\text { motorist } \\
\end{array}$ \\
\hline \multicolumn{7}{|c|}{ Large SUVs } \\
\hline 1980 & 166 & 45 & 114 & 16 & 156 & 38 \\
\hline 1981 & 164 & 60 & 117 & 14 & 164 & 43 \\
\hline 1982 & 93 & 24 & 72 & 8 & 80 & 25 \\
\hline 1983 & 111 & 33 & 83 & 18 & 72 & 19 \\
\hline 1984 & 98 & 38 & 77 & 10 & 97 & 20 \\
\hline 1985 & 128 & 49 & 101 & 15 & 149 & 31 \\
\hline 1986 & 168 & 60 & 128 & 20 & 194 & 46 \\
\hline 1987 & 146 & 76 & 117 & 20 & 190 & 41 \\
\hline 1988 & 155 & 80 & 111 & 25 & 202 & 49 \\
\hline 1989 & 164 & 76 & 115 & 24 & 219 & 61 \\
\hline 1990 & 185 & 83 & 127 & 21 & 249 & 57 \\
\hline 1991 & 165 & 83 & 116 & 22 & 204 & 58 \\
\hline 1992 & 117 & 57 & 92 & 21 & 222 & 52 \\
\hline 1993 & 122 & 74 & 88 & 21 & 211 & 49 \\
\hline 1994 & 148 & 76 & 92 & 31 & 229 & 60 \\
\hline 1995 & 152 & 63 & 118 & 23 & 289 & 63 \\
\hline 1996 & 141 & 80 & 98 & 33 & 256 & 77 \\
\hline 1997 & 145 & 96 & 106 & 28 & 312 & 61 \\
\hline 1998 & 203 & 99 & 147 & 27 & 282 & 68 \\
\hline \multicolumn{7}{|c|}{ Total SUVs } \\
\hline 1980 & 412 & 106 & 295 & 34 & 384 & 89 \\
\hline 1981 & 444 & 133 & 333 & 37 & 414 & 109 \\
\hline 1982 & 404 & 127 & 326 & 55 & 185 & 68 \\
\hline 1983 & 413 & 124 & 328 & 48 & 167 & 53 \\
\hline 1984 & 408 & 140 & 332 & 39 & 212 & 68 \\
\hline 1985 & 542 & 217 & 439 & 67 & 394 & 98 \\
\hline 1986 & 680 & 306 & 530 & 105 & 608 & 149 \\
\hline 1987 & 678 & 323 & 543 & 108 & 594 & 152 \\
\hline 1988 & 672 & 320 & 502 & 102 & 767 & 179 \\
\hline 1989 & 768 & 342 & 593 & 99 & 833 & 212 \\
\hline 1990 & 837 & 395 & 637 & 127 & 856 & 214 \\
\hline 1991 & 869 & 462 & 651 & 151 & 883 & 229 \\
\hline 1992 & 820 & 396 & 631 & 147 & 929 & 244 \\
\hline 1993 & 911 & 493 & 703 & 159 & 1,027 & 285 \\
\hline 1994 & 1,080 & 572 & 778 & 205 & 1,149 & 321 \\
\hline 1995 & 1,194 & 601 & 905 & 210 & 1,320 & 344 \\
\hline 1996 & 1,309 & 645 & 1,031 & 224 & 1,505 & 385 \\
\hline 1997 & 1,400 & 774 & 1,088 & 265 & 1,673 & 463 \\
\hline 1998 & 1,594 & 865 & 1,217 & 309 & 1,726 & 422 \\
\hline
\end{tabular}

Source: National Highway Traffic Safety Administration, "Traffic Safety CD-ROM" and FARS On-Line Query System at http://www-fars.nhtsa.dot.gov/www/query.html. 